\title{
Thermal conductivity of carbon nanotube networks:
}

\section{a review}

\author{
Bogumiła Kumanek $^{1, *}$ (1) and Dawid Janas ${ }^{1, *}$ (1) \\ ${ }^{1}$ Department of Chemistry, Silesian University of Technology, B. Krzywoustego 4, 44-100 Gliwice, Poland
}

Received: 24 September 2018

Accepted: 17 January 2019

Published online:

13 February 2019

(C) The Author(s) 2019

\begin{abstract}
Depending on their structure and order (individual, films, bundled, buckypapers, etc.), carbon nanotubes (CNTs) demonstrate different values of thermal conductivity, from the level of thermal insulation with the thermal conductivity of $0.1 \mathrm{~W} / \mathrm{mK}$ to such high values as $6600 \mathrm{~W} / \mathrm{mK}$. This review article concentrates on analyzing the articles on thermal conductivity of CNT networks. It describes various measurement methods, such as the 3- $\omega$ method, bolometric, steady-state method and their variations, hot-disk method, laser flash analysis, thermoreflectance method and Raman spectroscopy, and summarizes the results obtained using those techniques. The article provides the main factors affecting the value of thermal conductivity, such as CNT density, number of defects in their structure, CNT ordering within arrays, direction of measurement in relation to their length, temperature of measurement and type of CNTs. The practical methods of using CNT networks and the potential directions of future research in that scope were also described.
\end{abstract}

\begin{tabular}{|c|c|c|c|}
\hline & & LFA & Laser flash analysis \\
\hline & & MD & Molecular dynamic (simulation) \\
\hline List of sy & nbols & MWCNT & Multiwalled carbon nanotubes \\
\hline$A$ & Cross-sectional area & nd & No data \\
\hline AGF & Atomistic Green's Function & PSTTR & Phase-sensitive transient thermos- \\
\hline CNT & Carbon nanotube & & reflectance \\
\hline$C_{\mathrm{p}}$ & Specific heat & PTC & Parallel thermal conductance \\
\hline CVD & Chemical vapor deposition & $\mathrm{PyC}$ & Pyrolytic carbon \\
\hline$D$ & Diameter & $q$ & Density $\left(\mathrm{g} / \mathrm{cm}^{3}\right)$ \\
\hline DWCNT & Double-walled carbon nanotube & $R$ & Resistance \\
\hline f & Modulation frequency & ra- & Randomly aligned \\
\hline$I$ & Current & $S$ & Seebeck coefficient \\
\hline$k$ & Thermal conductivity & SPS & Spark plasma sintering \\
\hline$L$ & Length & SWCNT & Single-walled carbon nanotube \\
\hline
\end{tabular}

Address correspondence to E-mail: bogumila.kumanek@polsl.pl; dawid.janas@polsl.pl 


$\begin{array}{ll}t & \text { Thickness } \\ T / \Delta T & \text { Temperature/temperature gradient } \\ T_{\mathrm{m}} & \text { Temperature of measurement } \\ \mathrm{TE} & \text { Thermoelectric } \\ \mathrm{TIM} & \text { Thermal interfacial materials } \\ U & \text { Voltage } \\ \text { va- } & \text { Vertically aligned } \\ w & \text { Width } \\ \mathrm{ZT} & \text { Figure of merit } \\ \alpha & \text { Thermal diffusivity } \\ \sigma & \text { Electrical conductivity } \\ \mu & \text { Thermal penetration depth }\end{array}$

\section{Introduction}

We are facing quick technological developments, but also destruction of the natural environment, resulting from growing pollution and greenhouse effect. The sudden increase in energy use leads to growing consumption of non-renewable energy sources [1]. That is why scientists have been searching for new solutions for obtaining energy from alternative sources, such as solar [2] or wind sources [3], while reducing energy losses. In parallel, they have been developing the strategies to increase the overall efficiency of many processes by recovering waste heat using thermoelectric (TE) materials [4]. It is more and more obvious that for many real-life case processes proper thermal management is essential. As a consequence, a range of thermal interface materials (TIMs) [5] have been developed. Unfortunately, many of them are either expensive, toxic or have poor mechanical properties. Another disadvantage is that their thermal properties are not tunable, so one is restricted to use of certain materials for selected applications.

It seems impossible to find one material, which could solve this problem, but such material exists: carbon nanotubes (CNTs). Depending on their structure, form and method of synthesis, their thermal conductivity varies significantly, from $6600 \mathrm{~W} /$ $\mathrm{mW}$ [6] for individual SWCNTs up to the values that indicate they may even be thermal insulators for MWCNT bundled systems, for which thermal conductivity value is below $0.1 \mathrm{~W} / \mathrm{mK}[7,8]$. They have excellent mechanical properties and can be produced from renewable sources. In this study, we have compared the state of the art regarding thermal conductivity of CNT networks. We prepared a general overview of their performance and indicated the factors that determine the value of thermal conductivity. Key part of this review is a guideline how to measure the thermal conductivity of these materials. We concluded this review article with presentation of the most promising thermal applications of these carbon nanostructures.

\section{Thermal properties of CNTs}

Shortly after CNTs were observed by Iijima [9], calculations revealed that these tiny tubules made of carbon atoms have remarkable thermal properties. Reports on thermal conductivity values on the order of $10^{3} \mathrm{~W} / \mathrm{mK}[10,11]$ directed the attention of the scientific community to verify these predictions empirically. Once the anticipations were proven on the individual CNTs $[12,13]$, the immediate goal was to find a way to implement these wonder materials in the real-life applications. However, at this point, we experienced an unexpected twist. Ensembles of CNTs such as fibers or films turned out to be not as thermally conductive as expected or even insulating. There is no simple underlying reason for this phenomenon, but instead the problem is multidimensional.

Transport of thermal energy through a CNT is often considered to be dominated by the phonon conduction mechanism [13, 14]. Although some CNTs have metallic character and one could expect them to conduct thermal energy via electrons [15], the transport is still predominantly based on collective vibration of atoms [16, 17]. There are two main principles how the otherwise highly effective transport can be hindered. Firstly, despite using even the most precise reaction control systems, the CNTs are always born with defects. Topological defects such as those of Stone-Wales type or simple vacancies cause scattering, which decreases the mean free path of phonons. Secondly, CNTs always contain some form of extraneous contamination (other forms of carbon, residual catalyst, etc.), which must be removed not to interfere with thermal energy transport at high performance. Unfortunately, often removal of such unwanted species affects the structure of CNTs. Although globally the material is improved, local thermal resistance areas are introduced. It is also 
important to consider whether the CNTs are bundled or not as CNT-CNT coupling decreases thermal conductivity by an order of magnitude as related to isolated CNTs [18]. Although covalent cross-linking between individual CNTs has been considered as a possible solution to alleviate the problem of phonon propagation, one has to keep in mind that disrupting the network of $s p^{2}$ carbon atoms could introduce more scattering into the system. The length of individual CNTs also plays a role [19] and generally thermal conductivity increases with length up to the mean free path of phonons, which is about $500 \mathrm{~nm}$ for MWCNTs and longer for SWCNTs [20]. Furthermore, ensembles of CNTs are commonly composed of CNTs of different chiralities, each of which has a different band structure. As a consequence, we may expect that this relation would significantly affect the electronic contribution to the thermal conductivity [21]. Although as mentioned above the phonon-mediated thermal conductivity is predominant, such phenomenon can have an influence on the resulting performance as well. Polydispersity in terms of chiral angle also has a negative impact on the overall thermal conductivity of a CNT network as it increases the Kapitza resistance. (Two dissimilar CNTs can have different phonon spectra.)

It is evident that a system in which conduction of thermal energy is based on a plethora of intertwined CNTs is much more complex. Although it can be considered as troublesome that a wide range of parameters has to be optimized to reach a certain level of thermal conductivity, the situation can also work to our advantage. These parameters make CNT networks very tunable, and one could in theory tailor the same material to be either thermally insulating or conducting as required by specific application.

\section{Thermal conductivity molecular dynamic simulation}

The first literature reports from the beginning of the present century concerning thermal conductivity of CNTs were based on molecular dynamics simulation (MD simulation), which used the Tersoff-Brenner potential for $\mathrm{C}-\mathrm{C}$. This method was chosen from between the two known methods of predicting thermal transport properties of materials. In one of the methods, based on the Boltzmann equation, it is necessary to know the parameters obtained during measurements. However, thermal conduction measurements are still difficult, because it is technologically difficult to obtain well-ordered CNTs of high quality. As for the other method, MD simulation, it is only necessary to know the interatomic interaction for the system, because atom movements are completely regulated by the interatomic interactions described using quantum mechanics. That is why the first simulations by Berber and Osman were based on the Tersoff-Brenner potential and not on the Boltzmann equation.

Berber [6] conducted molecular dynamics simulations using the Tersoff potential to calculate the thermal conductivity of isolated $(10,10)$ CNTs and obtained an unusually high value $k=6600 \mathrm{~W} / \mathrm{mK}$ at room temperature. This result is comparable to the thermal conductivity of a hypothetical isolated graphene monolayer.

Osman et al. [22] focused on the relationship between the thermal conductivity and physical parameters of CNT. They calculated the thermal conductivity of several SWCNTs with different structure parameters for the range of temperatures of $100-500 \mathrm{~K}$. In their works, they considered various CNTs of armchair $(5,5),(8,8),(10,10),(12,12),(15,15)$ and zigzag structure $(10,0)$ of the length between 151 and $221 \AA$, with the number of atoms ranging from 1800 to 5400 . The aspect ratio between the length and diameter chosen in all the simulations was between 10 and 20. The publications examined a single nanotube and a single graphene layer which contained the same number of atoms. It was reported that the main feature of the course of thermal conductivity change in the function of temperature for SWCNT $(10,10)$ is similar to the course for monolayer of graphene and increases up to $400 \mathrm{~K}$ and then decreases. Furthermore, the authors informed that the thermal conductivity of SWCNT depends on the diameter of carbon nanotubes, and with their increase, the peak values of thermal conductivity appear at higher temperatures: For SWCNT $(5,5),(10,10)$ and $(15,15)$ it is 300, 400 and $450 \mathrm{~K}$, respectively. For CNTs with different chiralities but similar diameter, the maximum peaks of thermal conductivity are in the same temperature range $(300 \mathrm{~K})$, but the course of the curve is different-in the case of armchair CNTs it is sharper in comparison with zigzag CNTs. They explained it by different stiffness of $\sigma$ bonds which results from the particular chiral structure of CNTs. 
The theoretical considerations based on molecular dynamic simulation showed that the value of thermal conductivity for individual CNTs is nearing the value of a graphene monolayer. Additionally, it was found that temperature affects thermal conductivity, and up to a certain value, thermal conductivity increases to achieve the maximum and then decreases.

Che [23] concentrated on the theoretical considerations about the influence of vacancy or defect concentration on thermal conductivity of CNTs. The theoretical value of ideal SWCNTs measured along the tube axis is approximately $2980 \mathrm{~W} / \mathrm{mK}$. The simulation for SWCNTs with different concentrations of defects or vacancies showed that thermal conductivity decreased with increasing concentration of defects or vacancies as expected. Additionally, Che found that thermal conductivity changes when a CNT is not an individual CNT, but bundled together in close packing condition. The thermal conductivity along the axis is $950 \mathrm{~W} / \mathrm{mK}$, but in the perpendicular direction it is only $5.6 \mathrm{~W} / \mathrm{mK}$.

The other MD simulation for CNT bundle was conducted by Evans et al. [24]. They considered two types of bundle systems of CNT $(10,10)$ - parallel and crossbar arrays under different pressures, the structure of the crossbar and parallel system (Fig. 1a, b, respectively). The conductivity for the crossbar array is $0.028 \mathrm{~W} / \mathrm{mK}$ at atmospheric pressure and increases up to $0.05 \mathrm{~W} / \mathrm{mK}$ for the sample under $1 \mathrm{GPa}$. For the parallel array, under atmospheric, the calculated value of thermal conductivity is $0.55 \mathrm{~W} / \mathrm{mK}$, which is an order of magnitude higher than for the crossbar array. This results from the much greater

(a)

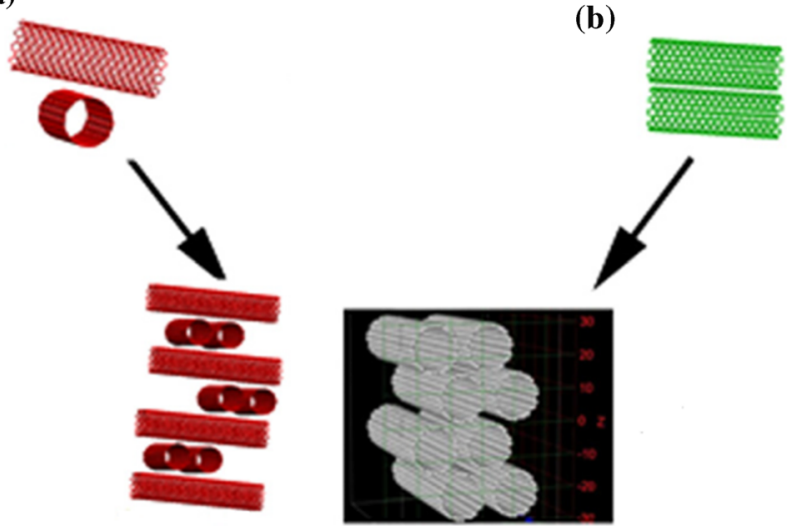

Figure 1 Structures of crossbar (a) and parallel bundle (b). Reprinted from Evans et al. [24], with the permission of AIP Publishing. contact area and better order of the bundle structure. In that case, pressure has much less effect on thermal properties. The authors concluded that pressure has two types of effect on junction conductance. First, the van der Waals bonding stiffness between the tubes is increased by the pressure. Second, the tubes are deformed by the pressure. In $90^{\circ}$ junctions, this leads to a significant increase in the contact area, while in parallel junctions it makes the shapes of the tubes oval, which limits the contact area. That is probably why the pressure effect on the conductance of parallel junctions is poorer.

MD simulation was used in multiple publications [14, 23-27]. It was mainly used for deliberations of the impact of physical parameters of nanotubes (such as diameter, length, chirality, density and presence of vacancies) on the value of thermal conductivity. What is more, it was applied to calculate the $k$ values for less obvious systems, such as SWCNT/DWCNT linked with polyethylene [27]. However, most of those works include speculations on single nanotubes, while only a few consider bundles [23, 24, 26]. This results from the fact that MD simulation is perfect for solving problems in the systems, in which anharmonicities are usually included in the interatomic potentials at high temperatures. For the arrays where harmonic scattering is dominant, resulting from interfaces contact or defects, thermal transport in materials is better described by Atomistic Green's Function (AGF).

Mathematical simulation for carbon nanotube pellets using AGF was used for the first time by Chalopin and Mingo et al. [26, 28]. In their study, they determined the values of thermal conductivity for the CNT pellets, in which the nanotubes of finite dimensions are in a randomly arranged network and cross each other at different points of their whole length. The important aspect of the calculations was assumption of three values: 1 -nanotube length, $d-$ nanotube diameter and $D$-average distance between cross junctions in a nanotube network, which served to determine the junction density $\left(1 / D^{3}\right)$. In their calculations, they also assumed the heat flow consistent with the model presented in Fig. 2. The results of mathematical simulations may be described using the following formula:

$k=\sigma \frac{0.18 l}{2 \pi d q_{\text {graphene }}} q_{\text {cnt film }}$ 
Figure 2 Model of heat flow in CNT junction. Reprinted from Chalopin et al. [28], with the permission of AIP Publishing.

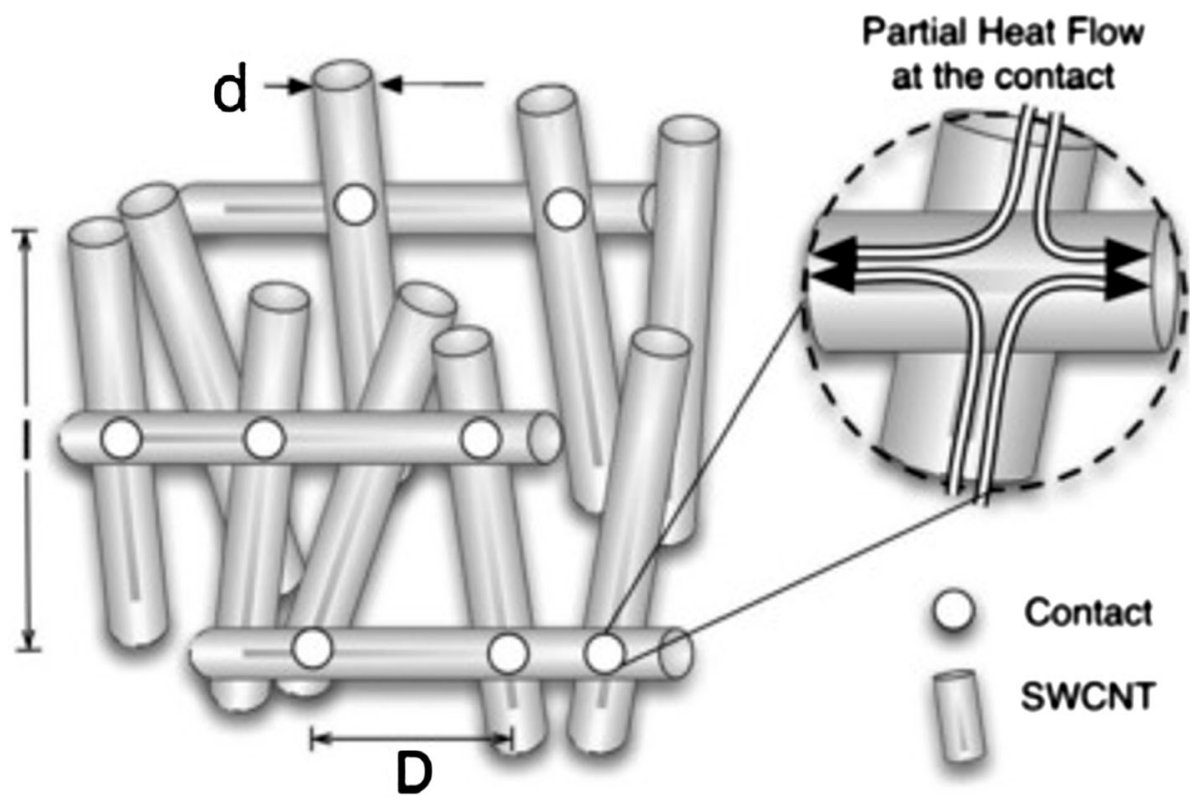

where $\sigma$ is a CNT-CNT contact conductance, $q_{\mathrm{CNT}}$ film is a density of CNT mat, $d$ is diameter of CNT and $l$ is length of CNT.

The conducted AGF simulation demonstrated that the thermal conductivity of nanotube pellets depends on mass density, chirality and diameter of the individual CNTs making up the pellets. The resulting thermal conductivity properties, depending on the selected physical parameters of CNTs and temperature in most cases, did not exceed $5 \mathrm{~W} / \mathrm{mK}$. The values are presented in Table 1.

Volkov et al. [29, 30] conducted a mesoscopic simulation based on a model of random thermal contacts between soft-core spherocylinders for continuous systems composed of CNTs $(10,10)$ of the density of $0.2 \mathrm{~g} / \mathrm{cm}^{3}$ in the length function CNT $\left(L_{\mathrm{T}}\right)$. The theoretical analysis of thermal properties of the material made up of CNTs demonstrated that thermal properties mainly depend on intertube thermal contact resistance. In their research, they examined a 3D network and a 2D film. The network consisted of disordered nanofibers (made of CNT bundles), and the simulations were conducted both in the in-plane and out-plane directions (Fig. 3 red and blue lines, respectively). The film consisted of randomly oriented layers of CNTs. In summary, the theoretical analysis of nanofibrous materials with thermal transport properties governed by interfiber contact resistance suggests a strong quadratic dependence on the length of the nanofibers for the thermal conductivity of isotropic 3D systems of randomly dispersed straight nanofibers and in-plane conductivity of quasi-2D films composed of disordered layers of nanofibers. In-plane 3D CNT networks demonstrate much better thermal conductivity properties than films, which is caused by efficient heat transfer along the bundles.

\section{Instrumental method of thermal properties measurements}

Examination of the thermal properties of materials, including thermal conductivity, has always been challenging due to the number of parameters that need to be taken into account in the tests. These include heat losses, not to be taken into consideration so that we may determine correctly the heat flux through the sample.

Measurements of thermal conductivity could be conducted by different techniques. Some of them are more popular, such as 3- $\omega$ technique, comparative method, steady heat method or self-heating method, but some scientists create their own sets of tests. Below, we have presented some of these methods and described them in short, focusing on the most important elements and differences.

Thermal conductivity measurement methods can be classified depending on the heating procedure. The methods where the sample has direct contact with the heater are called contact-heating method. On 
Table 1 Thermal conductivity calculated by mathematical simulation

\begin{tabular}{|c|c|c|c|}
\hline Type of mathematic simulation & Type of CNT & $K(\mathrm{w} / \mathrm{mK})$ & References \\
\hline MD with Tersoff potential & Isolated CNT $(10,10)$ & 6600 & [6] \\
\hline \multirow[t]{7}{*}{ MD with Tersoff-Brenner potential } & CNT $(10,10)$ at $100 \mathrm{~K}$ & 950 & {$[22]$} \\
\hline & $\mathrm{CNT}(10,10)$ at $200 \mathrm{~K}$ & 1050 & \\
\hline & CNT $(10,10)$ at $300 \mathrm{~K}$ & 1500 & \\
\hline & CNT $(10,10)$ at $400 \mathrm{~K}$ & 2800 & \\
\hline & $\mathrm{CNT}(5,5)$ at $300 \mathrm{~K}$ & 2200 & \\
\hline & $\mathrm{CNT}(15,5)$ at $300 \mathrm{~K}$ & 1500 & \\
\hline & $\mathrm{CNT}(10,0)$ at $300 \mathrm{~K}$ & 2200 & \\
\hline \multirow[t]{13}{*}{ MD with Brenner potential } & CNT $(10,10)$ with 400 atoms & 2390 & {$[23]$} \\
\hline & CNT $(10,10)$ with 800 atoms & 2450 & \\
\hline & CNT $(10,10)$ with 1600 atoms & 3050 & \\
\hline & CNT $(10,10)$ with 3200 atoms & 2980 & \\
\hline & CNT $(10,10)$ with 6400 atoms & 2900 & \\
\hline & CNT $(10,10) 200 \AA$ Aith 0.002 vacancy concentration & 1300 & \\
\hline & CNT $(10,10) 200 \AA$ with 0.005 vacancy concentration & 700 & \\
\hline & CNT $(10,10) 200 \AA$ with 0.01 vacancy concentration & 450 & \\
\hline & CNT $(10,10) 200 \AA$ Aith 0.00075 defect concentration & 2980 & \\
\hline & CNT $(10,10) 200 \AA$ with 0.00125 defect concentration & 2100 & \\
\hline & CNT $(10,10) 200 \AA$ with 0.0025 defect concentration & 1250 & \\
\hline & CNT $(10,10)$ bundles along tube & 950 & \\
\hline & CNT $(10,10)$ bundles across tube & 5.6 & \\
\hline \multirow[t]{2}{*}{ Non-equilibrium MD } & CNT $(10,10)$ crossed bundles & 0.028 & {$[24]$} \\
\hline & CNT $(10,10)$ parallel bundles & 0.55 & \\
\hline \multirow[t]{9}{*}{ AGF } & $\operatorname{CNT}(8,8)$ film $d=1.1 \mathrm{~g} / \mathrm{cm}^{3}$ & 3.5 & {$[28]$} \\
\hline & $\operatorname{CNT}(7,7)$ film $d=1.2 \mathrm{~g} / \mathrm{cm}^{3}$ & 4.4 & \\
\hline & $\operatorname{CNT}(6,6)$ film $d=1.5 \mathrm{~g} / \mathrm{cm}^{3}$ & 3.4 & \\
\hline & $\operatorname{CNT}(5,5)$ film $d=1.75 \mathrm{~g} / \mathrm{cm}^{3}$ & 2.8 & \\
\hline & $\operatorname{CNT}(9,0)$ film $d=1.65 \mathrm{~g} / \mathrm{cm}^{3}$ & 3.3 & \\
\hline & $\operatorname{CNT}(8,0)$ film $d=1.85 \mathrm{~g} / \mathrm{cm}^{3}$ & 3.0 & \\
\hline & $\operatorname{CNT}(7,0)$ film $d=2.15 \mathrm{~g} / \mathrm{cm}^{3}$ & 3.1 & \\
\hline & $\operatorname{CNT}(5,0)$ film $d=3.0 \mathrm{~g} / \mathrm{cm}^{3}$ & 4.5 & \\
\hline & $\operatorname{CNT}(10,0)$ film $d=1.5 \mathrm{~g} / \mathrm{cm}^{3}$ & 4.7 & \\
\hline
\end{tabular}

the other hand, the techniques where the sample was heated using radiation are called non-contact-heating method. The first group includes, among others, 3- $\omega$, bolometer and steady-state methods. Non-contact methods include, among others, laser flash analysis (LFA), thermoreflectance method and Raman spectroscopy.

\section{Contact methods}

\section{Third-harmonic method}

The third-harmonic method (3- $\omega$ method) is commonly used in measurement of thermal properties of bulk materials and films [31-39], in which the sample is heated using alternating current with $\omega$ frequency. A temperature variation with $2 \omega$ frequency was induced in the sample while heating, and a drop in voltage with $3 \omega$ frequency was recorded across the heater.

Figure 4 shows the schematic of the measurement setup (a) and electronic circuit of the experimental setup (b). The experimental setup is equipped with a lock-in integrated circuit in a chamber, which isolated the sample from room conditions, and connected to an electric circuit. A very important element of the measurement setup, the diagram of which is presented in Fig. 4, is a metal bridge. It is both a heater and a thermometer. A precisely controlled source of 


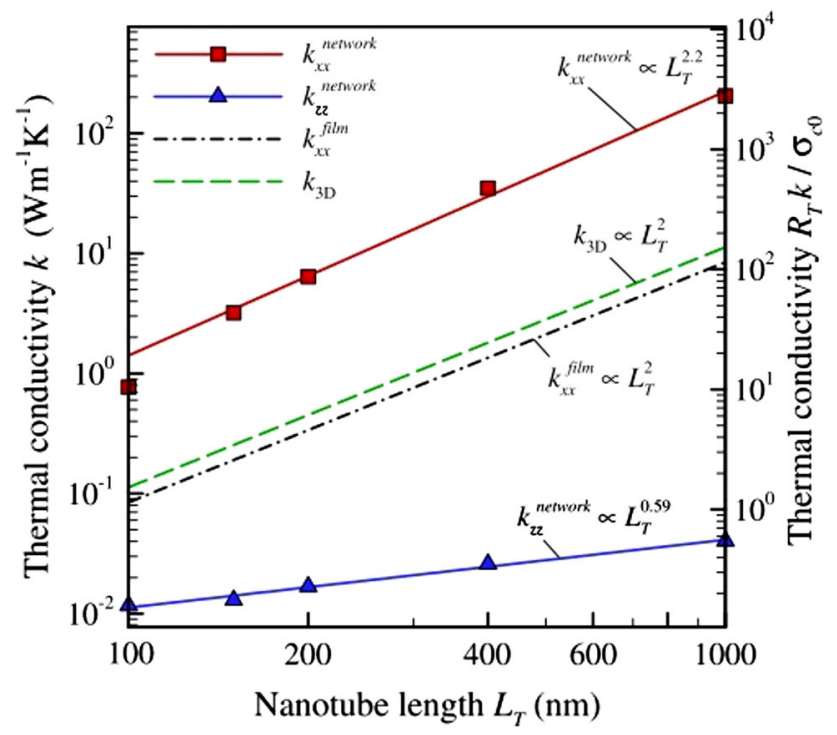

Figure 3 Thermal conductivity calculated by mesoscopic simulation for anisotropic networks of CNT. Reprinted with permission from Volkov et al. [29]. Copyright (2010) by the American Physical Society.

$\mathrm{AC}$ is used during the experiment to prevent overvoltage which could damage the CNT sample.

The bridge is usually a metal wire made of gold [31] or platinum [32]. By applying voltage, the bridge generates heat and causes temperature differences in 2- $\omega$ oscillation. The created temperature oscillations are very closely connected to the thermal properties of the sample. Additionally, it should be noted that the electrical resistance of the metal bridge is proportional to its temperature, and therefore, that resistance is also modulated in 2- $\omega$ frequency. Using

(a)

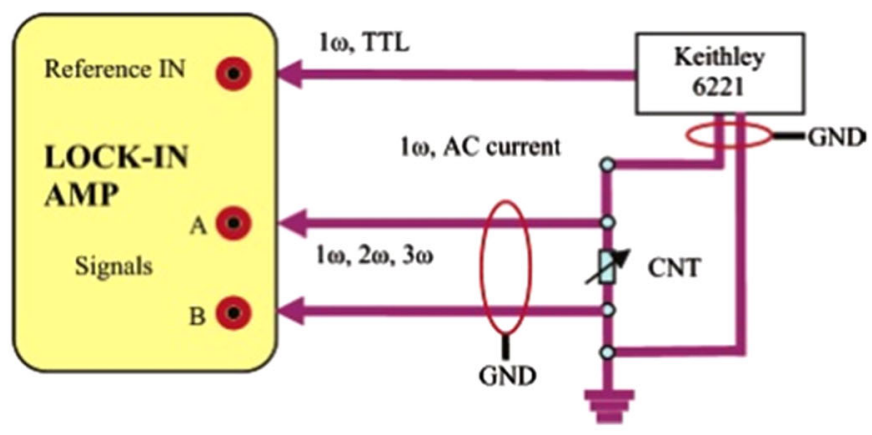

Figure 4 Schematic setup of 3 omega method (a) [34] and electronic circuit of the experimental setup (b) [102]. Reprinted with permission from Choi et al. Copyright (2006) American an integrated amplifier for removing the noise, the setup measures the drop in the voltage of the frequency of $3 \omega$. The value of thermal conductivity results from the following Formula 2.

$k=\frac{4 I^{3} R R^{\prime} L}{\pi^{4} U_{3 \omega} A}$

where $R$ is the specimen resistance between the potential electrode, $R$-temperature gradient of the resistance at the given temperature, $L$-distance between potential electrodes, $A-$ cross-sectional area of sample, $I$-current of $\mathrm{AC}$, and $U_{3 \omega}$-third-harmonic voltage signal.

In that method, it is necessary to properly fabricate the test devices. A layer of CNT is placed on a substrate limiting heat losses, usually silicon wafer. Next under the pressure the CNT layer is pressed into the sensor. The sensor is a multilayer set, based on glass [33] or polymer [31], on which a metal bridge covered with an insulation layer is fixed to insulate the electric conductive bridge from the CNT sample. Figure 5 presents a schematic of the manner of preparing the sample [33].

The 3- $\omega$ method is often used for measuring thermal conductivity of thin films such as CNT films. This method was adapted to measurements of thermal conductivity of CNTs and first used by Choi et al. $[32,34]$. They conducted the research using two-point measurements for a single MWCNT $(650 \mathrm{~W} / \mathrm{mK})$ and compared them with the results for a MWCNT covered with a layer of platinum $(830 \mathrm{~W} / \mathrm{mK})$. In the next publication, they determined the value of

(b)

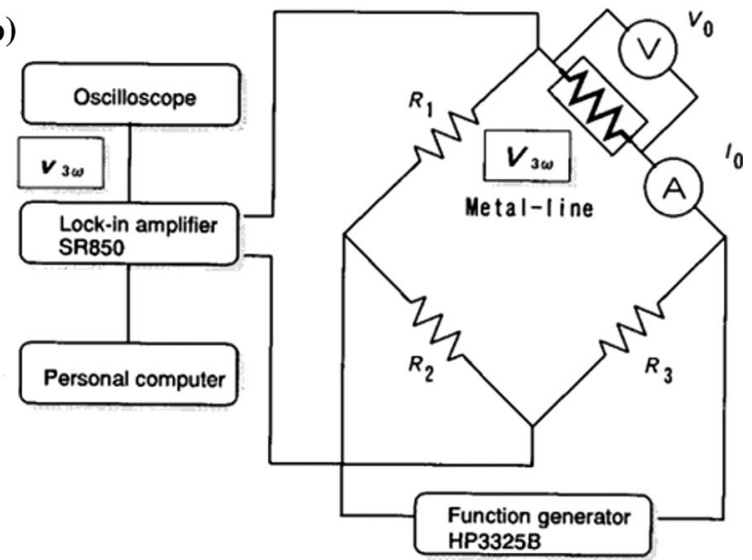

Chemical Society. Reprinted from Yamane et al. with the permission of AIP Publishing. 


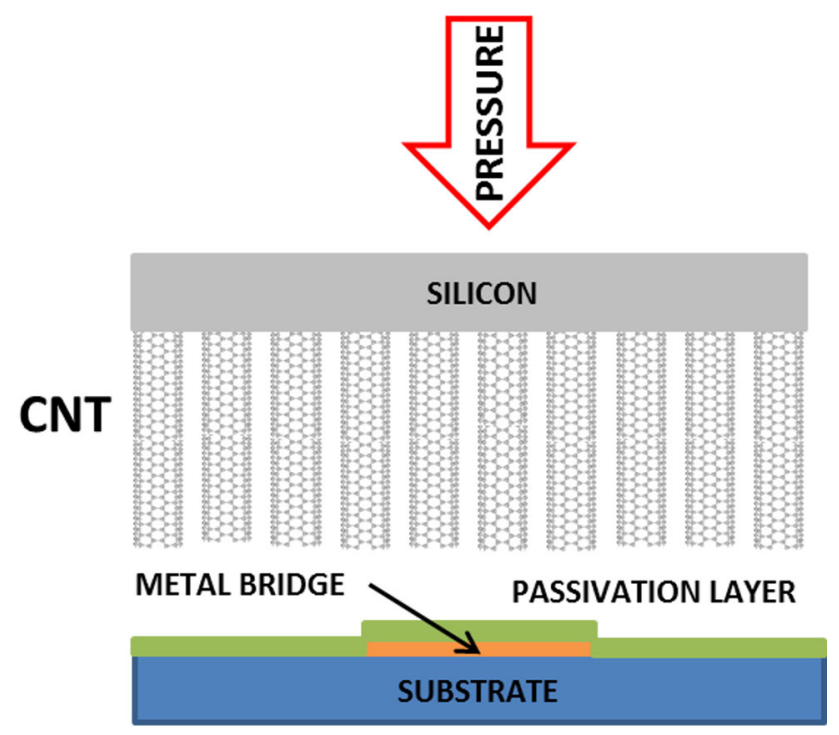

Figure 5 Schematic of the experimental set in 3- $\omega$ methods. Created based on $\mathrm{Hu}$ et al. [33].

thermal conductivity for a single MWCNT using four-point 3- $\omega$ measurement. The value of conductivity was $k=300 \pm 20 \mathrm{~W} / \mathrm{mK}$. It is one order of magnitude lower than in the theoretical deliberations for individual SWCNTs, which the authors explained through intertube dispersion of phonons and nonharmonic Umklapp's scattering, which is the main mechanism of scattering in MWCNTs at room temperature. That paper provided the guidelines for other scientists to use this method to measure CNT films.

\section{Steady-state method}

The steady-state thermal characterization technique, shown in Fig. 6a, consists of measuring the drop across temperature of samples placed between a heater and a heat sink [40,41]. The method is based on the definition that thermal conductivity is the thermal energy transmitted through a sample of the length of $\mathrm{L}$ and depends on cross section $A$, temperature difference (hot and cold end) in the steady state of heat transmission and is described using Formula (3):

$k=\frac{Q L}{A \Delta T}$

where $Q$ is the amount of thermal energy flowing through a sample which is described by equation $Q=p-Q_{\text {loss }}$ where $p$ is the applied heating power (a)
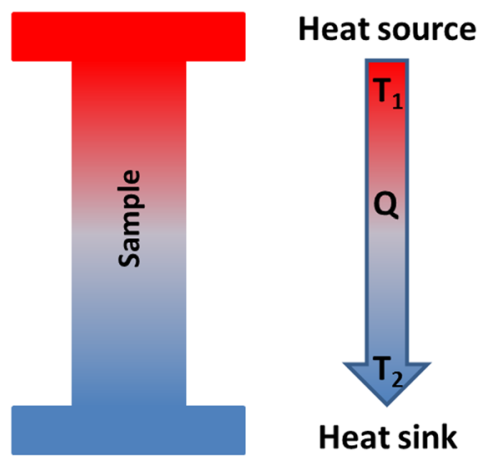

(b)

Figure 6 Scheme of steady-state $\mathbf{a}$ and PTC $\mathbf{b}$ measurement setups. Created based on Zhao et al. [103].

and $Q_{\text {loss }}$ is the parasitic heat loss due to radiation, conduction and convection to the ambient. $L$ and $A$ are parameters of the sample: length and crosssectional area, and $\Delta T$ is the temperature difference between the temperature sensors.

The measurement is relatively straightforward [42], but a lot of effort must be exercised to minimize heat loss. The heat loss effect through radiation, heat conducted through the thermocouple and heater lead wires as well as the impact of thermal properties of the gas surrounding the sample (heat conduction and convection) affect the measurement error of sample thermal conductivity. What also counts is the thermocouple measurement sensitivity when determining $\Delta T$ along the sample. That is why, it is necessary to provide a vacuum for the measurement in order to limit the impact of heat conduction and convection losses and to apply shielding in order to limit radiation losses.

Due to the relatively easy measurement, several variations of that method were developed, such as the parallel thermal conductance and steady-state method with IR thermometer. That group of methods also includes the comparative method.

Parallel thermal conductance (PTC) is a 1D steadystate measurement method different from the classic 1D steady-state method. Conductance is higher in the background than in the sample itself and has to be determined accurately and subtracted.

The method is particularly useful for the samples which are not rigid enough to support the heaters and the thermometer, so it may be successfully applied mainly to measurements of certain CNT yarns $[43,44]$, but also CNT sheets $[45,46]$. Figure $6 \mathrm{~b}$ 
provides a schematic presentation of the measurement setup in the PTC method.

The disadvantages of that method include the fact that the samples measured have to be relatively large-the length of ca. $80 \mathrm{~mm}$ is required for films or yarns. One of the advantages is that one may measure elastic samples without the rigidity required by the classic steady-state method.

\section{Steady-state method with IR thermometer}

Another variant of the steady-state method differs from the original one with the manner of recording the sample temperature distribution while alternating current of specific amperage flows through the sample. Instead of the classic thermocouples to measure the value of $\Delta T$, the changes in temperature of the sample as a function of its length may be recorded using an IR thermometer [47, 48] or IR microscope [49]. Then, proper calculations are made on the basis of the results obtained, and the value of thermal conductivity is determined. The method was applied by Zhang [47], Wang [48] and Liu [49].

Figure 7 provides a schematic presentation of the measurement setup. A CNT bundle or cut film is placed, using silver paste, on the electrodes (copper $[48,49]$ or aluminum [47]). The whole measurement setup is placed on an insulating substrate (wooden [47], plastic [49] or glass [48]). The measurements are taken in a vacuum chamber in order to reduce the impact of the ambient environment.

The measurements provided a distribution of temperatures on the whole length of the sample, with the highest temperature $T_{\mathrm{m}}$ in the middle of the sample. Knowing the values of applied voltage and resistance as well as the physical parameters of the sample, the value of thermal conductivity may be calculated using Formula 4 [48].

$k=\frac{U * I * 1 / 2 l}{4 w t\left(T_{m}-T_{o}\right)}$

where $U$ is the voltage, $l$ is the current, $w$ and $t$ are the length, width and thickness of the sample, and $T_{\mathrm{o}}$ is the temperature in which the measurement is takenusually $300 \mathrm{~K}$.

\section{Comparative method}

Thermal conductivity measurement using the comparative method consists of measuring the decreases in temperature on a rod for which the conductivity to temperature relationship is known, and on a sample. In order to make the measurement, the sample of specific dimensions is placed in a series using a rod (made of reference material) with a temperature sensor, as presented in Fig. 8. A heater heats the hot end up and generates a heat flow through the sample and rod made of reference material to the cold end. Thermal conductivity may be calculated on the basis of the values of temperature in along the sample and rod while heating. The whole setup is calibrated on the basis of the standards with known temperaturedependent thermal conductivity necessary for calculating the thermal conductivity of the sample, described with Formula 5 [41].

$k=k_{\mathrm{r}} \frac{\Delta T_{\mathrm{r}}}{\Delta T_{\mathrm{s}}} \frac{\Delta z_{\mathrm{s}}}{\Delta z_{\mathrm{r}}}$

where $k$ and $k_{\mathrm{r}}$ are the thermal conductivity of the sample and reference material, $\Delta T_{\mathrm{s}}$ and $\Delta T_{\mathrm{r}}$ are the temperature difference in the sample and in the reference material, $\Delta z_{\mathrm{s}}$ and $\Delta z_{\mathrm{r}}$ are the sensor distance in the sample and in the reference material.

\section{Hot-disk method}

The transient planar source technique also called the hot-disk technique is proper for measurements of thermal conductivity of thin samples, such as CNT films. In this method, an insulated sensor is located between two identical parts of a sample, and it constitutes a heat source and a thermometer at the same time. Thermal conductivity is described by Formula 6.

$\Delta T \sqrt{\frac{t_{\mathrm{m} \alpha}}{r^{2}}}=\frac{P}{\pi^{3 / 2} r K} D(\tau)$

where $\alpha$ is thermal diffusivity, tm is transient measurement time, $r$ is radius of the sensor, $P$ is input heating power and $D(\tau)$ is a Bessel function [8]. The time and the input power are selected so that the heat flow is within the boundaries of the sample and so that the outer boundaries of the sample are not affected by the increase in temperature of the sensor. 
Figure 7 Scheme of steadystate measurements setup with IR thermometer. Reprinted with permission from Zhang et al. [47] Copyright (2012) American Chemical Society.

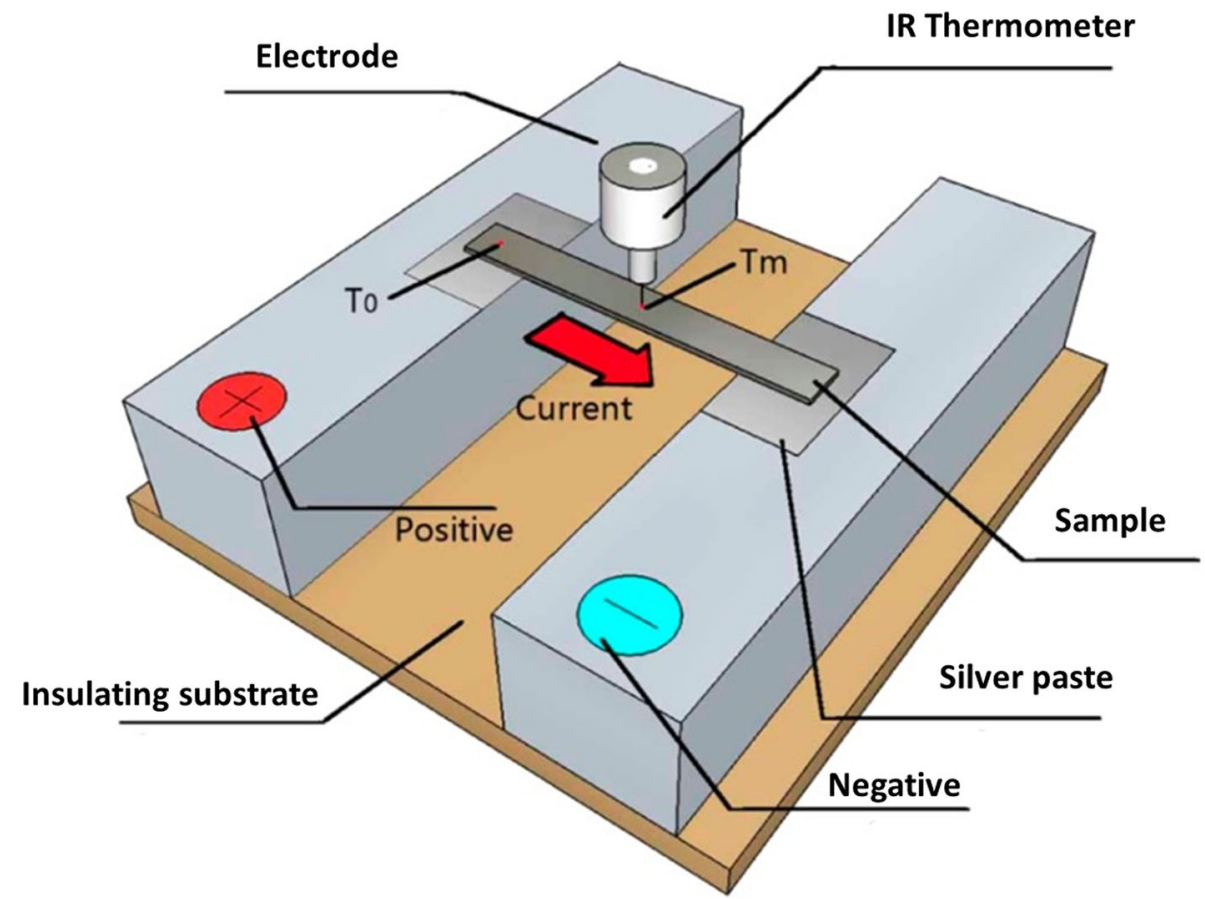

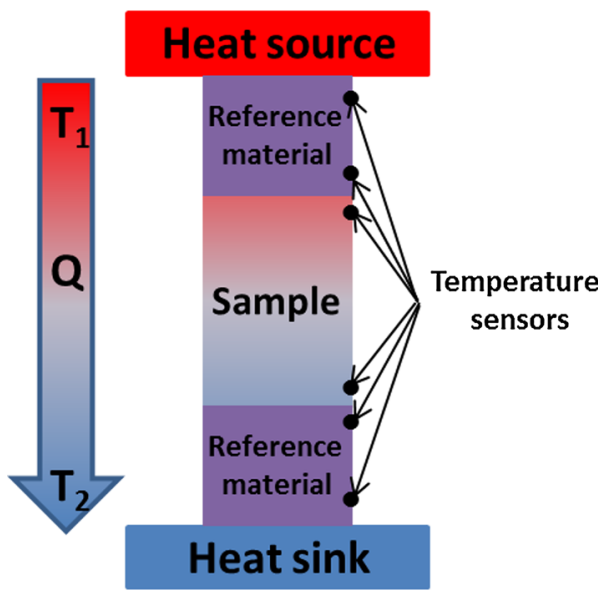

Figure 8 Scheme of measurement comparative method setup. Created based on Brütting et al. [104].

\section{Non-contact methods}

\section{Frequency-domain technique}

The frequency-domain technique is a group of measurement techniques including according to Abad et al. [54], among others, laser flash analysis, thermoreflectance method and photothermal technique. All the variations of that method are based on heating up a sample using a laser beam of modulated frequency and registering the thermal waves and periodic temperature distribution. Additionally, this method depends on the relationship between the thermal diffusivity and modulation frequency of the laser as described by Formula 7 .

$\mu=\sqrt{\frac{\alpha}{\pi f}}$

where $\mu$ is a thermal penetration depth, $\alpha$ is a thermal diffusivity and $f$ is a modulation frequency.

Laser flash analysis (LFA), also called laser flash method, was described for the first time by Parker et al. [50]. That method allows determination of the thermal diffusivity of the material. The measurement consists of irradiating one side of the sample using a flash lamp, usually xenon lamp, while at the same time measuring the change in temperature on the other side of the sample using an IR detector. The measurement setup is presented in Fig. 9.

The temperature of the backside over time is plotted. The value of thermal diffusivity is usually determined by fitting the data to different models taking into account the boundary conditions of the measurement setup.

This method is described using the following Formula 8.

$\alpha_{0.5}=\frac{1.37 l^{2}}{\pi^{2} t_{0.5}}$

where $t_{0.5}$ is the time in which the rear of the sample reaches half-maximum in its rise in temperature, 


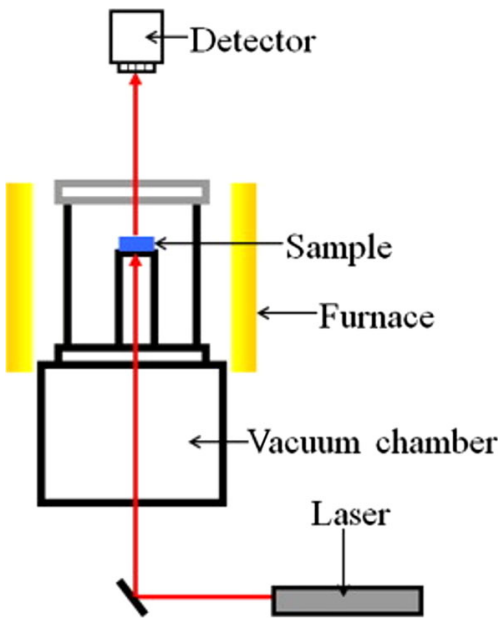

Figure 9 Scheme of LFA measurements setup. Reprinted from An et al. [105] with permission from Elsevier.

$\alpha_{0.5}$ - the calculated thermal diffusivity using $t_{0.5}$, and l-sample thickness.

The equation is based on the following assumptions:

1. heat flow is one-dimensional;

2. absorption of energy is instantaneous, because the pulse width of the incident laser is negligible in comparison with the characteristic transit duration of the heat flux through the sample,

3. the laser does not penetrate inside the sample,

4. measured parameters ( $\alpha$ and $C p$ ) are highly temperature-dependent,

5. sample surfaces have negligible heat losses.

The thermoreflectance method (also called phase-sensitive transient thermoreflectance technique PSTTR) was described for the first time by Ohsone et al. [51] for solid samples. This method consists of irradiation of a sample on a surface with a high-power laser which causes periodical temperature oscillations. Another laser, of smaller power, irradiates the sample directly. The intensity of the reflected signal and its phase depend on the thermal properties of the sample and may be applied to determine those properties, including the thermal conductivity and thermal contact conductance of the material. Figure 10 presents the diagram of the experimental array of PSTTR.

The samples for measuring thermal conductivity using PSTTR are prepared by deposition of a vertically aligned CNT on a silicon wafer using the CVD method and then by covering the sample with a top surface.

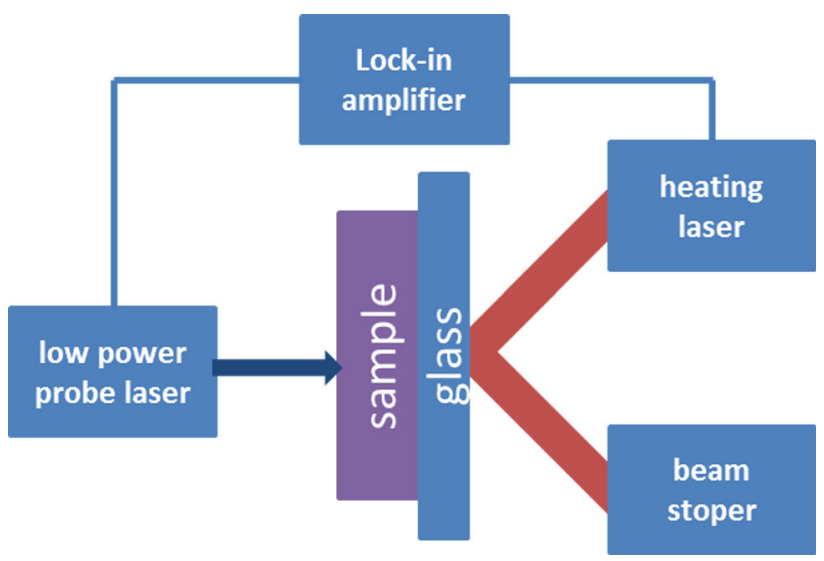

Figure 10 PSTTR measurement array diagram. Created based on Panzer et al. [54].

In that method, in order to be able to measure a sample, it is necessary to prepare the measurement set very carefully. For that reason, that method is effectively used for assessing thermal conductivity of arrays containing a CNT layer which may be potentially applied as TIM, because by measuring the system, we learn of its total characteristics, and not only those of the carbon layer.

The technique was also used by Tong et al. [52, 53]. They conducted measurements for three samples of MWCNT array obtained on a silicon wafer during CVD synthesis, using ethylene as precursor accompanied by a Fe catalyst. In their study, using a series of differently prepared samples, they verified how the top surface affects the resulting thermal conductivity values. The first samples were prepared without top surface, and the heating laser was absorbed directly at the top surface of MWCNT. The second sample was obtained with top surface made from glass plate, and the last one included surface made from indium layer which thermally welded MWCNTs on the glass. It was observed that the value of thermal conductivity without the top-surface layer $(244 \mathrm{~W} / \mathrm{mK})$ is lower than in the case of arrays with that layer $(265 \mathrm{~W} / \mathrm{mK}$ and $267 \mathrm{~W} / \mathrm{mK})$. Additionally, the type of layer has small impact on conductivity.

Panzer et al. [54] conducted measurements of the $\mathrm{Al} / \mathrm{Pd} / \mathrm{CNT} / \mathrm{SiO}_{2} / \mathrm{Si}$ array. They obtained modest values of $k$ for CNT (ca. $8 \mathrm{~W} / \mathrm{mK}$ ). They explained it by presenting a model of heat transportation in an array with vertically aligned CNT on Si wafers covered top surface (Fig. 11). They also suggested a simple geometric model for the incomplete CNT- 
metal thermal contact. Taking into account different lengths of CNTs and roughness of the film, it may be found that only some CNTs take effective part in heat transportation, while at the same time providing resistance for the remaining nanotubes.

The conducted study demonstrated that the thermoreflectance method is effective for measuring conductivity of layered arrays containing carbon nanotubes, but in order to obtain credible results, the measurement array would have to be prepared correctly. Table 2 summarizes thermal conductivity measurement by thermoreflectance method.

The photothermal technique was suggested by Wang et al. [58] for thermal analysis of samples of highly aligned MWCNTs. A correctly prepared sample allows to determine the thermal conductivity of a CNT layer, as well as to determine the thermal contact resistance between the $\mathrm{CNT}$ and the substrate. A sample analyzed during measurement consists of three layers. A thin film of $\mathrm{Cr}$ on silicon and then vaMWCNT is placed on it. The substrate is a silicon wafer, because of its weak absorption of the IR laser beam and because it is transparent for thermal radiation of the $\mathrm{Cr}$ layer. The structure of the sample is presented in Fig. 12. The sample set was irradiated from the backside (from the silicon wafer side) and the beam caused direct heating of the $\mathrm{Cr}$ layer and induced temperature variation at the $\mathrm{Cr}$ surface. Heat conduction along the CNT is closely correlated to temperature changes which are sensitive to the thermal radiation measured. The measured value of thermal conductivity along the axial direction of vaMWCNTs amounted to $0.145 \mathrm{~W} / \mathrm{mK}$ for the whole film and $27.3 \mathrm{~W} / \mathrm{mK}$ for an individual nanotube in that film [58].

\section{Raman spectroscopy}

For the first time Raman spectroscopy was used for measurement of thermal conductivity of materials (in this case a porous silicon) by Perichon et al. [60]. The irradiated material has capacity for elastic or inelastic scattering. If the energy of the reflected light is lower, it is called Stokes Raman scattering, and if higheranti-Stokes Raman scattering, and the given shifts are characteristic for the given type of material. The surface temperature in the place heated with laser may be measured in one of two ways: first by examining the Stokes shift as a function of temperature and second by examining the ratio of intensity of Stokes and anti-Stokes peaks, but these are more difficult to measure.

As Stokes peaks and anti-Stokes peaks are typical for the given measurement, by analyzing their shifts, it is possible to determine the change in temperature of the sample surface and use that data for determining the value of thermal conductivity on the basis of the following relationship (Formula 9) [61]:

$k=\frac{A * P}{l\left(T_{\text {Raman }}-T_{\sin k}\right)}$

where $A$ is a cross section of the sample, $l$ is length of the sample, $P$ is the power of laser, $T_{\text {Raman }}$ is the measured temperature and $T_{\text {sink }}$ is the temperature of heat sink.

In the case of analysis of CNT samples, a prominent peak was observed at ca. $1590 \mathrm{~cm}^{-1}$ at room

Figure 11 Diagram of thermal conductivity via layered samples of metallized CNT. Created based on Panzer et al. [54].

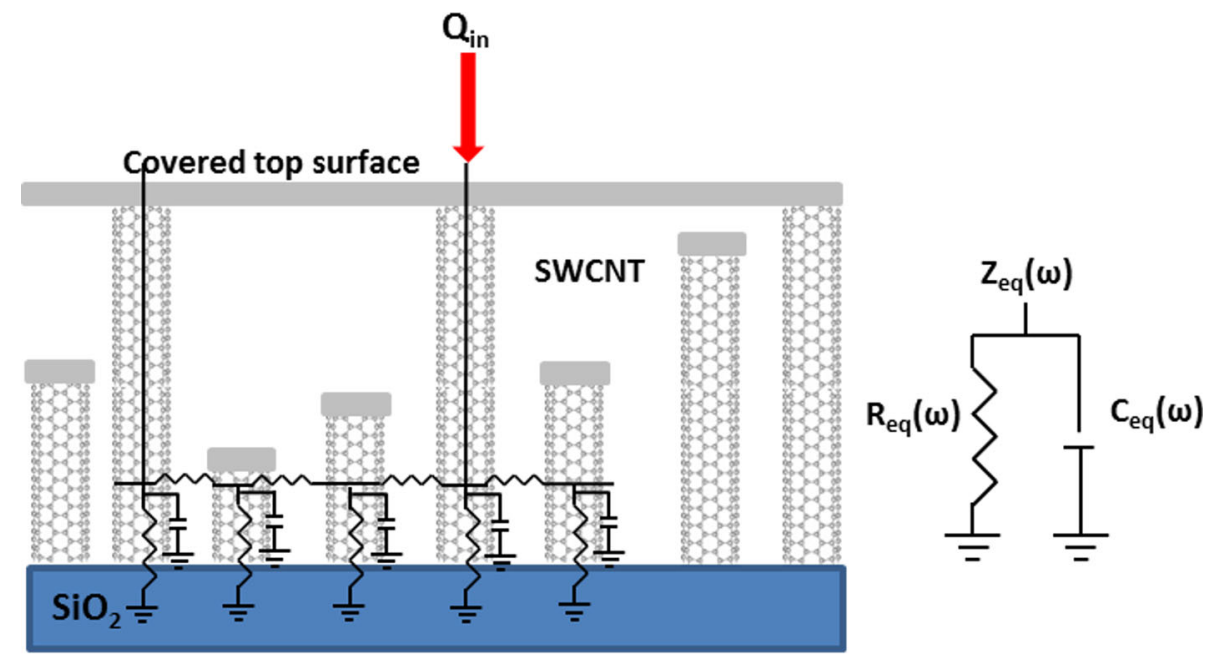


Table 2 Thermal conductivity of layered arrays with layer of CNTs

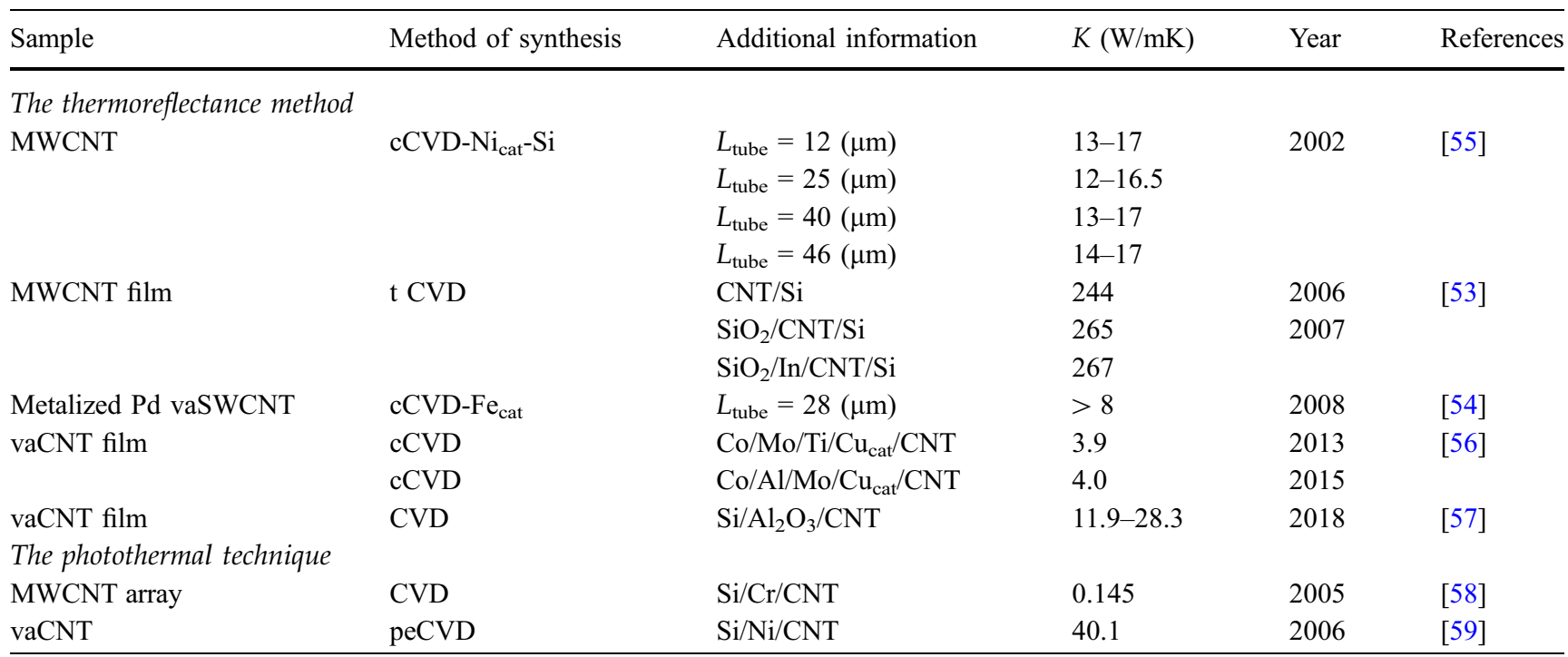

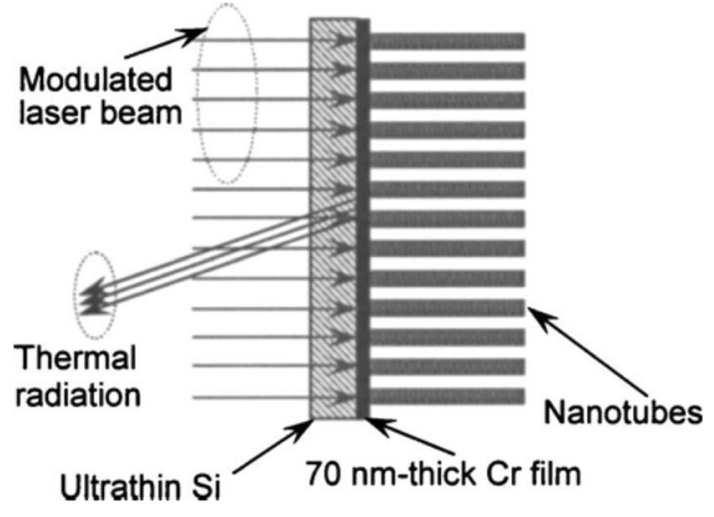

Figure 12 Schematic of sample-laser beam relation in photothermal technique. Reprinted from Wang et al. [58], with the permission of AIP Publishing.

temperature, the so-called G-band. That signal appears in all the carbon materials, which contain $s p^{2}$ bonds. For SWCNTs, the G-band can be in fact deconvoluted into multiple individual peaks. In a Raman spectrum of CNTs, G+ and G- signals can be observed, but the intensity of $\mathrm{G}+$ is much higher than that of $\mathrm{G}-$ and so that signal is used for analyzing the spectrum. Figure 13 presents a spectrum with marked G+ peak and its visible shift with temperature for a CNT sample [62].

The samples are usually measured in a thermostated vacuum chamber. Such conditions provide limited heat dissipation, so the laser energy is mainly used for local heating of the sample. By decreasing

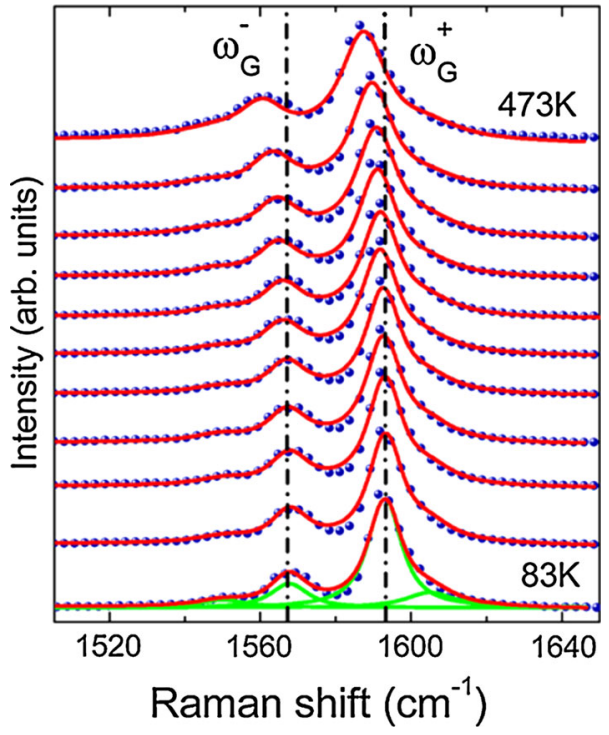

Figure 13 Raman spectra of CNT with shifted G+ peak. Adapted from Sahoo et al. [62]. Reprinted with permission. Copyright (2014) American Chemical Society.

the laser power, the local temperature of the sample is changed. The main advantages of that method include the fact that the measurement is contactless; it does not damage the sample and does not require special preparation. Additionally, that technique provides submicron resolution, so it is good for measuring nanostructures.

The first attempts to measure thermal conductivity of CNTs using Raman spectroscopy were performed 
by $\mathrm{Li}$ et al. [63], who used it for measurement of thermal properties of an individual SWCNT and MWCNT and obtained 2400 and $1400 \mathrm{~W} / \mathrm{mK}$, respectively.

\section{Bolometric technique}

The bolometric technique for thermal property measurements of thin $(<100 \mathrm{~nm})$, semitransparent SWCNT films of nanogram mass was used by Itkis et al. [64]. IR radiation was used as a heating source and generated a triangular temperature profile along the SWCNT sample. In this method, a sample is also a thermometer. The sample is suspended across the opening sapphire ring using Ag paste which provides efficient heat sink. The set is placed in a cryostatic chamber under the pressure of $<0.1$ mTorr. A bolometer is used to measure the photoresponse of the sample to IR radiation. The thermal conductivity in that method is described with Formula 10:

$k=\frac{P_{\mathrm{abs}}}{\Delta T} * \frac{L}{8 A}$

where $P_{\mathrm{abs}}$ is the power of the absorbed IR radiation, $L$ is the length and $A$ is the cross-sectional area of the SWCNT film.

\section{Thermal conductivity of CNT networks}

Impact of general characteristics of CNT ensembles The comprehensive research conducted by Aliev et al. [35, 36] had significant effect on understanding the impact of structure and ordering of nanotubes in materials. They used the 3- $\omega$ technique to conduct measurements for MWCNT sheets of different length of samples at different temperatures and different number of layers [35] and for various CNT sets [36]single MWCNTs, bundled MWCNTs and aligned and freestanding MWCNT sheets. Figure 14a presents the results for three types of samples of MWCNT sheets of different lengths: $7.6 \mathrm{~mm}, 5.4 \mathrm{~mm}$ and $0.37 \mathrm{~mm}$ which were marked with red, green and blue open dots, respectively. The experiment results demonstrated that up to $150 \mathrm{~K}$, the length of MWCNT sheets is of no significance for the value of thermal conductivity, which is probably caused by a large reduction in radiation. Above $150 \mathrm{~K}$, it was observed that conductivity values are higher for much longer samples than for short samples (Fig. 6a). They also measured the value of conductivity along and across the obtained film of the length of $0.37 \mathrm{~mm}$ at the temperature of $295 \mathrm{~K}$ and were provided with the values at the level of $50 \mathrm{~W} / \mathrm{mK}$ and $2.1 \mathrm{~W} / \mathrm{mK}$, respectively. In the multilayer systems, they observed deterioration in thermal conductivity as a result of a rise in the number of layers, which is presented in Fig. 14b [35]. They explained the low value of thermal conductivity for MWCNT sheets with two factors: internal defects of the respective nanotubes and phonon boundary scattering in bundles forming the basis for MWCNT sheets.

In their next paper, they concentrated on the systems containing differently oriented MWCNTs-single, bundled and sheets. Additionally, they proposed a model of heat flow through a tube-tube interface. When two nanotubes are at the distance of van der Waals forces, heat is transferred from the outermost shell of CNT 1 to the outermost shell of CNT 2, along the CNT2, and then onto CNT 3 and so forth. This concept was graphically depicted in the study by Qiu et al. [37]. Figure 15a presents the schematic of heat transfer between shells of neighboring nanotubes, and Fig. 15b shows the thermal resistance network in the forms of electrically equivalent circuits of resistors.

It suggested that MWCNTs are better than SWCNTs for thermal conductivity, because the increase in diameter of nanotubes is accompanied by more optical phonon modes which may be subject to excitation and contribute to thermal conductivity. In the case of appearance of a defect in the SWCNT structure, its impact on conductivity properties is much stronger than in the case of MWCNTs. This results from the fact that in MWCNTs, the neighboring shell could create new additional channels for phonons, which is impossible in SWCNT.

In their research [36], they obtained the following values of thermal conductivity for a single MWCNT, bundled MWCNTs and MWCNT film: 600, 150 and $50 \mathrm{~W} / \mathrm{mK}$, respectively. Low thermal conductivity may be explained by low structural quality of MWCNTs obtained through CVD. Through experiments, they proved that bundling decreases thermal conductivity. Additionally, the thermal conductivity of a CNT bundle and CNT film is much lower than that of a single nanotube, which results from much poorer energy transfer between the tubes which, in turn, results from the small connecting surface areas of cylindrical tubes and poor transfer of phonons. Also, they calculated that the best thermal 

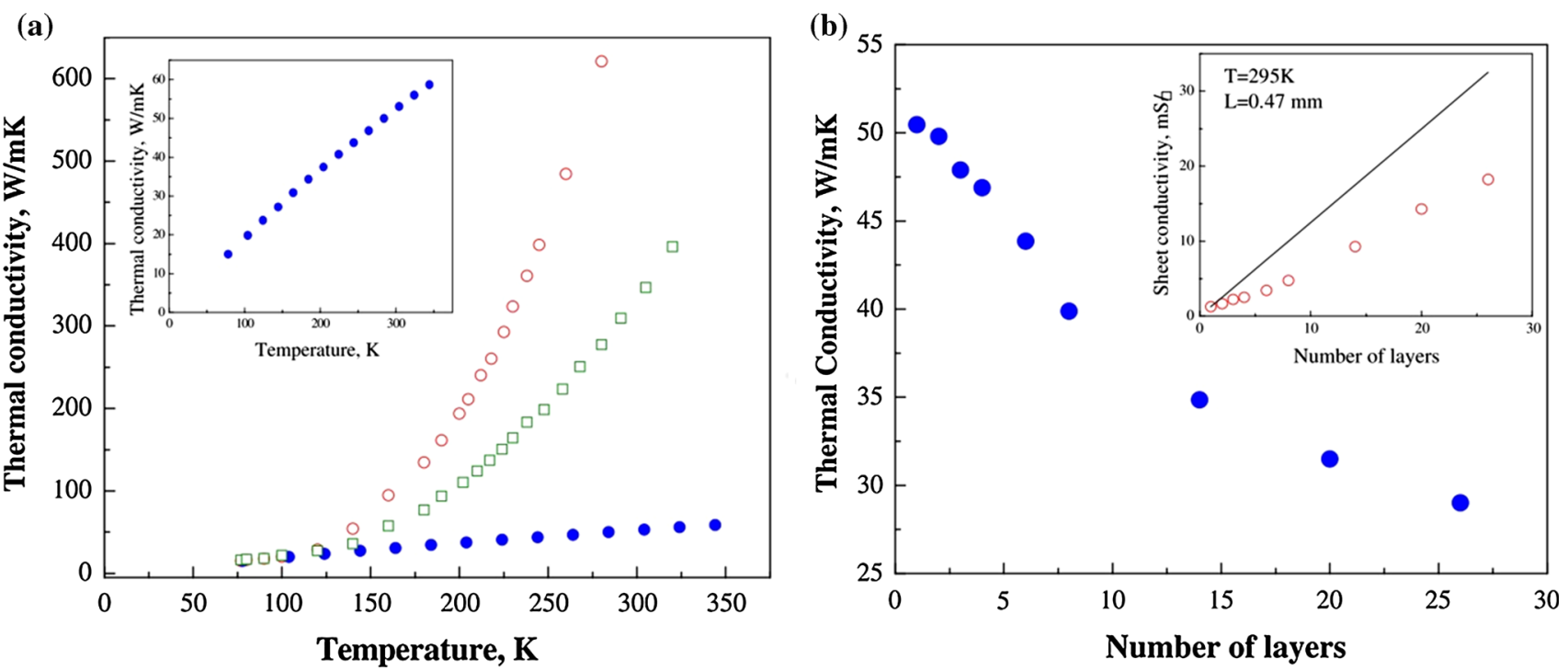

Figure 14 Thermal conductivity of CNT sheets depends on length (a) and number of layers (b). Reprinted from Aliev et al. [35], with permission from Elsevier.

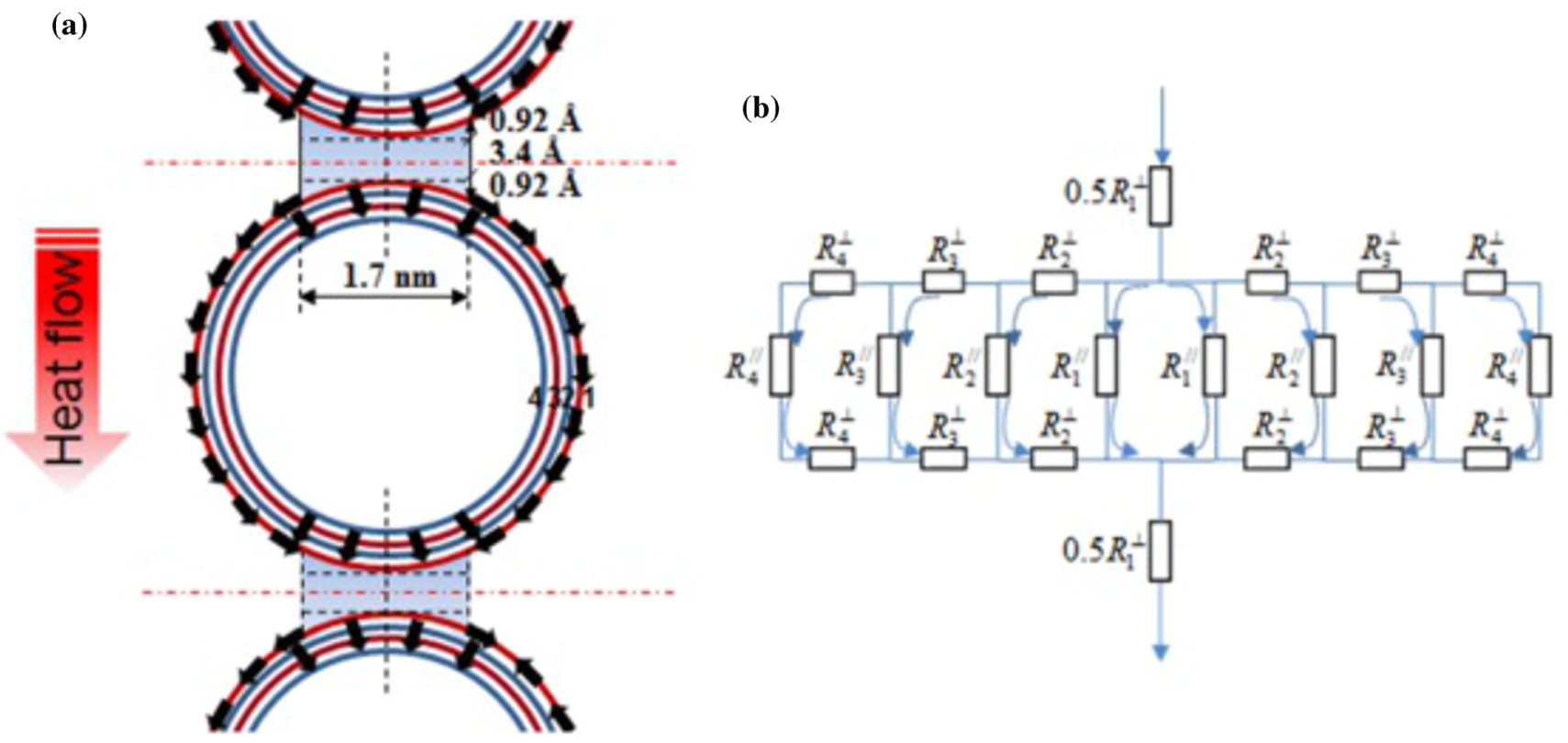

Figure 15 Scheme of phonon transport between neighboring nanotubes. Reprinted from Qiu et al. [37] with permission from Nature Research Journal.

conductivity in long CNT bundles appears when single nanotubes overlap at only $2-3 \%$.

The thermal properties of nanotubes are highly affected by synthesis parameters. The process of synthesis impacts the type (SWCNT, DWCNT or MWCNT), the number of defects in the crystalline network as well as the contaminants present in the material. The research into the impact of synthesis conditions and contaminants on thermal properties of CNT films were conducted by Ivanov et al. [65] and Gspann et al. [46]. They stated that synthesis conditions may be used to control the physical parameters of nanotubes and the degree of crystallinity and to reduce the amount of contaminants in the film which have a negative impact on thermal and electrical conductivity, because they disrupt contact between bundles. 
The thermal conductivity of nanotubes is also affected by the presence of other nanotubes in their close vicinity. The conducted experimental research confirms the theoretical calculations described above (part 3). In the case of CNTs, an increase in bundle size decreases thermal conductivity [66]. This results from increased scattering rate with neighboring CNTs. What is more, research was conducted that demonstrated that a CNT bundle is characterized by higher values of thermal conductivity than films, which results from the fact that in bundles, nanotubes are mainly parallel, while in films there additionally appears the crossbar structure which has a negative impact on the conductivity of phonons.

Yoshida et al. [67] conducted the research into the impact of stacking several films and into changes in anisotropic properties of such systems. They noticed that an increase in the number of films causes a reduction in anisotropy and an increase in thermal conductivity.

Table 3 lists the measurement results for various systems based on CNTs.

\section{Impact of temperature}

Various methods are commonly applied to measure the impact of temperature on thermal conductivity. Some are more suitable for measurements at lower temperatures-below $275 \mathrm{~K}$, such as comparative methods and PTC. Others, because of the measurement method, e.g., the need to irradiate a sample with laser, work better in measurements of thermal conductivity at the temperatures above room temperature. These include LFA and conductivity measurement using Raman spectroscopy.

In order to properly understand the impact of temperature on thermal conductivity of carbon nanotube networks, a single nanotube should be examined first. In the lowest temperature ranges close to absolute zero, thermal conductivity increases linearly with increase in temperature and the heat transport is ballistic [70]. With further increase in temperature, thermal conductivity starts to be mediated by additional phonon modes and thermal conductivity rises until reaching the maximum value (which is often close to room temperature [6, 22]). Then, the increase in temperature causes domination of photon scattering processes [10], which reduce thermal conductivity.
Literature has numerous references for research into thermal conductivity of various CNT networks: films, buckypapers or bundled CNTs in the function of temperature. The research conducted by Hone et al, Gonnet et al. and Pöhls et al. has demonstrated that the films obtained from CNTs demonstrate an increase in thermal conductivity together with an increase in temperature, between near $0 \mathrm{~K}$ and about room temperature, which might have been expected from examination of changes in thermal conductivity for a single nanotube. Hone et al. [12] were the first researchers to determine the relationship between thermal conductivity and temperature for high-purity mats of tangled single-walled carbon nanotubes. They noted that the thermal conductivity smoothly decreased from 210 to near $0 \mathrm{~W} / \mathrm{mK}$ with decreasing temperature in the range from $350 \mathrm{~K}$ to below $40 \mathrm{~K}$, respectively.

The second group of research found in the literature includes measurements taken from room temperature upward. Hu et al. [33] conducted research for a vaCNT layer at two different temperatures using the 3- $\omega$ method. They observed a rise in thermal conductivity from $74 \mathrm{~W} / \mathrm{mK}$ (for room temperature) to $83 \mathrm{~W} / \mathrm{mK}$ (for the temperature of $323 \mathrm{~K}$ ).

In a subsequent study, Zhang et al. [71] analyzed the change in the value of thermal conductivity at different temperatures of the bulk MWCNTs annealed at $1600{ }^{\circ} \mathrm{C}$. They observed that the maximum peak occurred at the temperature of $900 \mathrm{~K}$ when the value of thermal conductivity was $4.9 \mathrm{~W} /$ $\mathrm{mK}$, while above that temperature the conductivity began to decrease.

Examinations of thermal conductivity of SWCNT film and determination of the temperature for which it reaches the maximum value were performed by Duzynska and Zdrojek et al. [72-74]. They obtained an SWCNT film and then examined the impact of elevated temperature on changes in thermal conductivity using Raman spectroscopy. It follows from their research that thermal conductivity decreased from 26.4 to $9.2 \mathrm{~W} / \mathrm{mK}$ in the temperature range from 300 to $450 \mathrm{~K}$. Additionally, they observed a plateau from the level of $410 \mathrm{~K}$. They explained a decrease in conductivity value in an SWCNT film by increasing higher-order phonon scattering processes with rise in temperature. Table 4 lists the results of the research of thermal conductivity in the function of temperature available in the literature. 
Table 3 Impact of general characteristics of CNT ensembles

\begin{tabular}{|c|c|c|c|c|c|c|}
\hline \multicolumn{7}{|l|}{ Impact of characteristic } \\
\hline Type of CNT & $\begin{array}{l}\text { Method of } \\
\text { synthesis }\end{array}$ & $\begin{array}{l}\text { Method of } \\
\text { measurement }\end{array}$ & $\begin{array}{l}\text { Additional } \\
\text { information }\end{array}$ & $\begin{array}{l}K(\mathrm{~W} / \\
\mathrm{mK})\end{array}$ & Year & References \\
\hline MWCNT sheet $(L=0.37 \mathrm{~mm})$ & \multirow[t]{5}{*}{ cCVD } & \multirow[t]{8}{*}{ 3- $\omega$ method } & $295 \mathrm{~K} /$ parallel & 50 & \multirow[t]{5}{*}{2007} & \multirow[t]{5}{*}[35]{} \\
\hline MWCNT sheet & & & $\begin{array}{l}295 \mathrm{~K} / \\
\text { perpendicular }\end{array}$ & 2.1 & & \\
\hline MWCNT yarn & & & $295 \mathrm{~K}$ & 26 & & \\
\hline MWCNT sheet $(L=7.6 \mathrm{~mm})$ & & & $275 \mathrm{~K}$ & 650 & & \\
\hline MWCNT sheet $(L=5.4 \mathrm{~mm})$ & & & $295 \mathrm{~K}$ & 310 & & \\
\hline Individual MWCNT & \multirow[t]{3}{*}{$\mathrm{pCVD}$} & & $275 \mathrm{~K}$ & 600 & \multirow[t]{3}{*}{2010} & \multirow[t]{3}{*}[36]{} \\
\hline Bundled MWCNT & & & $275 \mathrm{~K}$ & 150 & & \\
\hline MWCNT sheet & & & $275 \mathrm{~K}$ & 50 & & \\
\hline CNT buckypapers & \multirow[t]{2}{*}{ CVD } & \multirow[t]{2}{*}{ Steady state } & \multirow[t]{2}{*}{ Diameter $>30$} & 0.46 & \multirow[t]{2}{*}{2012} & \multirow[t]{2}{*}[68]{} \\
\hline $\begin{array}{l}\text { CNT buckypaper impregnated with } \\
\text { silicon oil }\end{array}$ & & & & 1.09 & & \\
\hline \multirow[t]{7}{*}{ CNT film } & $\begin{array}{l}\text { CVD methane } \\
\text { C:Fe } 1900\end{array}$ & PTC method & In-plane $300 \mathrm{~K}$ & 110 & \multirow[t]{7}{*}{2017} & \multirow[t]{7}{*}[46]{} \\
\hline & CVD toluene & & & 67 & & \\
\hline & $\mathrm{C}: \mathrm{Fe} 400$ & & & & & \\
\hline & CVD n-butanol & & & 30 & & \\
\hline & $\mathrm{C}: \mathrm{Fe} 800$ & & & & & \\
\hline & CVD n-butanol & & & 7 & & \\
\hline & $\mathrm{C}: \mathrm{Fe} 1450$ & & & & & \\
\hline Hybrid film SWCNT + MWCNT & CVD & LFA & & 8.3 & 2007 & [69] \\
\hline \multirow[t]{3}{*}{ SWCNT } & \multirow[t]{3}{*}{ Aerosol CVD } & \multirow[t]{3}{*}{ Raman spectroscopy } & 1-layer & 25.4 & \multirow[t]{3}{*}{2017} & \multirow[t]{3}{*}[67]{} \\
\hline & & & 2-layers & 50.5 & & \\
\hline & & & 3-layers & 64.0 & & \\
\hline \multirow[t]{4}{*}{ SWCNT } & \multirow[t]{4}{*}{ CVD } & \multirow[t]{4}{*}{ Steady state } & Isolated & 4500 & \multirow[t]{4}{*}{2018} & \multirow[t]{4}{*}[66]{} \\
\hline & & & 4-CNT bundle & 1800 & & \\
\hline & & & 8-CNT bundle & 280 & & \\
\hline & & & 13-CNT bundle & 180 & & \\
\hline
\end{tabular}

\section{Impact of density}

Both specific density and packing density of CNTs in a film have a significant impact on the value of thermal conductivity of CNT networks. An increase in thermal conductivity is associated with an increase in the number of junctions, which facilitated heat transport within the sample. The literature demonstrates various methods of increasing density of the systems made up of CNTs. The first one consists in annealing a sample, thus increasing its ordering and crystallinity (described in detail in the next subchapter). Other methods consist in a mechanical increase in packing of CNTs in a film, e.g., by pressing them using different pressures. Table 5 lists the results of the research of thermal conductivity correlated with density of samples.

Prasher et al. [26, 79] researched the impact of density in buckypaper systems, where SWCNTs are randomly oriented. On the basis of Formula (1), they used mathematical simulation to determine the theoretical value for their materials. Also, they observed it was one order of magnitude higher than the experimental results presented in Table 5 .

Zhang et al. [47] examined the impact of density of CNT packing in buckypapers on the value of thermal conductivity. In their work, they used different pressures in the range of 20 to $30 \mathrm{MPa}$ in order to press the sample. The density of samples was in the range of 0.8 to $1.39 \mathrm{~g} / \mathrm{cm}^{3}$. The authors emphasized that the highest value of density of the sample packed 
Table 4 Impact of temperature to the thermal conductivity of CNT networks

\begin{tabular}{|c|c|c|c|c|c|c|}
\hline Type of CNT & $\begin{array}{l}\text { Method of } \\
\text { synthesis }\end{array}$ & Method of measurement & $\begin{array}{l}\text { Temperature of } \\
\text { measurement }\end{array}$ & $\begin{array}{l}K(\mathrm{~W} / \\
\mathrm{mK})\end{array}$ & Year & References \\
\hline $\begin{array}{l}\text { Bulk SWCNT } \\
\text { Aligned by filtration and high magnetic field }\end{array}$ & nd & $\begin{array}{l}\text { Comparative method } \\
\text { measured in alignment } \\
\text { direction }\end{array}$ & $\begin{array}{l}50 \mathrm{~K} \\
100 \mathrm{~K} \\
150 \mathrm{~K} \\
200 \mathrm{~K} \\
250 \mathrm{~K} \\
300 \mathrm{~K}\end{array}$ & $\begin{array}{l}10 \\
55 \\
110 \\
150 \\
190 \\
210\end{array}$ & $\begin{array}{l}1999 \\
2000 \\
2002\end{array}$ & $\begin{array}{l}{[12]} \\
{[75,76]}\end{array}$ \\
\hline vaCNTs layer & pCVD & $3-\omega$ method & $\begin{array}{l}295 \mathrm{~K} \\
323 \mathrm{~K}\end{array}$ & $\begin{array}{l}74 \\
83\end{array}$ & 2006 & {$[33]$} \\
\hline SWCNTs mats & nd & Comparative method & $\begin{array}{l}150 \mathrm{~K} \\
225 \mathrm{~K} \\
300 \mathrm{~K}\end{array}$ & $\begin{array}{l}15 \\
28.5 \\
42\end{array}$ & 2006 & {$[77]$} \\
\hline SWCNTs mats aligned under $17.3 \mathrm{~T}$ & & & $\begin{array}{l}150 \mathrm{~K} \\
225 \mathrm{~K} \\
275 \mathrm{~K}\end{array}$ & $\begin{array}{l}4 \\
12 \\
20\end{array}$ & & \\
\hline SWCNT randomly oriented mats & & & $\begin{array}{l}150 \mathrm{~K} \\
225 \mathrm{~K} \\
300 \mathrm{~K}\end{array}$ & $\begin{array}{l}6 \\
12.5 \\
18\end{array}$ & & \\
\hline MWCNT & $\begin{array}{l}\text { CVD/ } \\
\text { SPS1600/ } \\
5 \mathrm{~min}\end{array}$ & LFA & $\begin{array}{l}300 \mathrm{~K} \\
600 \mathrm{~K} \\
900 \mathrm{~K} \\
1000 \mathrm{~K}\end{array}$ & $\begin{array}{l}2.8 \\
4.3 \\
4.9 \\
4.6\end{array}$ & 2007 & {$[71]$} \\
\hline CNT array & Commercial & LFA & $\begin{array}{l}300 \mathrm{~K} \\
400 \mathrm{~K}\end{array}$ & $\begin{array}{l}60 \\
100\end{array}$ & 2007 & {$[78]$} \\
\hline $\begin{array}{l}3 \mathrm{CNT} \text { sheet with different widths: } 0.6,0.8 \\
\text { and } 0.9 \mathrm{~mm} \text { and length } 4.2 \mathrm{~mm} \text { (mix) }\end{array}$ & $\begin{array}{l}\text { Water- } \\
\text { assisted } \\
\text { CVD }\end{array}$ & PTC & $\begin{array}{l}50 \mathrm{~K} \\
100 \mathrm{~K} \\
200 \mathrm{~K} \\
250 \mathrm{~K} \\
300 \mathrm{~K}\end{array}$ & $\begin{array}{l}0.5 \\
1.1 \\
1.75 \\
2.25 \\
2.54\end{array}$ & 2012 & {$[45]$} \\
\hline $\begin{array}{l}\text { CNT sheet } 3.6 \mathrm{~mm} \text { width and } 4.2 \mathrm{~mm} \\
\text { length }\end{array}$ & & & $\begin{array}{l}50 \mathrm{~K} \\
100 \mathrm{~K} \\
200 \mathrm{~K} \\
250 \mathrm{~K} \\
300 \mathrm{~K}\end{array}$ & $\begin{array}{l}0.45 \\
0.8 \\
1.4 \\
1.8 \\
2.25\end{array}$ & & \\
\hline SWCNT film & Commercial & Raman spectroscopy & $\begin{array}{l}300 \\
340 \\
380 \\
410\end{array}$ & $\begin{array}{l}26.4 \\
18 \\
13.5 \\
9.2\end{array}$ & 2015 & {$[73]$} \\
\hline
\end{tabular}

at the highest pressure is very similar "to the ultimate density 1.58 of ideal buckypapers-calculated by a simple hexagonal close packing model." The conductivity was measured using steady-state methods, and an increase from 472 to $766 \mathrm{~W} / \mathrm{mK}$ was observed. The research confirmed that thermal conductivity increases with increasing density, which results from higher packing of CNTs in a sample which, in turn, results in more readily reached thermal percolation.

The steady-state method was also used by Pöhls et al. [45] to examine the CNT obtained using CVD water-assisted method. The thermal conductivity of that sample amounted to $3.0 \mathrm{~W} / \mathrm{mK}$ at room 
Table 5 Impact of density

\begin{tabular}{|c|c|c|c|c|c|c|}
\hline Type of CNT & Method of synthesis & $\begin{array}{l}\text { Method of } \\
\text { measurement }\end{array}$ & $\begin{array}{l}\text { Additional } \\
\text { information }\end{array}$ & $\begin{array}{l}K(\mathrm{~W} / \\
\mathrm{mK})\end{array}$ & Year & References \\
\hline $\begin{array}{l}\text { 1-2 nm SWCNT random array } \\
\text { film }\end{array}$ & nd & $\begin{array}{l}\text { Steady-state } \\
\text { method }\end{array}$ & $\begin{array}{l}p=20(\mathrm{psi})^{\mathrm{a}} \\
p=50(\mathrm{psi})^{\mathrm{a}} \\
p=90(\mathrm{psi})^{\mathrm{a}}\end{array}$ & $\begin{array}{l}0.155 \\
0.175 \\
0.194\end{array}$ & 2009 & {$[26,79]$} \\
\hline $\begin{array}{l}<8 \mathrm{~nm} \text { MWCNT random } \\
\text { array film }\end{array}$ & nd & & $\begin{array}{l}p=20(\mathrm{psi})^{\mathrm{a}} \\
p=50(\mathrm{psi})^{\mathrm{a}} \\
p=90(\mathrm{psi})^{\mathrm{a}}\end{array}$ & $\begin{array}{l}0.154 \\
0.171 \\
0.195\end{array}$ & & \\
\hline $\begin{array}{l}60-100 \mathrm{~nm} \text { MWCNT random } \\
\text { array film }\end{array}$ & & & $\begin{array}{l}p=20(\mathrm{psi})^{\mathrm{a}} \\
p=50(\mathrm{psi})^{\mathrm{a}} \\
p=90(\mathrm{psi})^{\mathrm{a}}\end{array}$ & $\begin{array}{l}0.134 \\
0.154 \\
0.170\end{array}$ & & \\
\hline Aligned buckypapers CNT & $\begin{array}{l}\text { CVD + pressed with different } \\
\text { pressures }\end{array}$ & & $\begin{array}{l}d=0.8\left(\mathrm{~g} / \mathrm{cm}^{3}\right) \\
d=0.85\left(\mathrm{~g} / \mathrm{cm}^{3}\right) \\
d=1.1\left(\mathrm{~g} / \mathrm{cm}^{3}\right) \\
d=1.39\left(\mathrm{~g} / \mathrm{cm}^{3}\right)\end{array}$ & $\begin{array}{l}472 \\
525 \\
600 \\
766\end{array}$ & 2012 & {$[47]$} \\
\hline $\begin{array}{l}\text { Primary CNT array (vaCNTs } \\
\text { film) }\end{array}$ & $\mathrm{pCVD}$ & $3-\omega$ method & $T_{\mathrm{m}}=295 \mathrm{~K}$ & 9.3 & 2018 & {$[31]$} \\
\hline $\begin{array}{l}\text { Secondary CNT array (3D } \\
\text { network) }\end{array}$ & & & $T_{\mathrm{m}}=295 \mathrm{~K}$ & 19.8 & & \\
\hline vaCNT (out-of-plane) & CVD & & - & $\begin{array}{l}17.9 \\
21.5\end{array}$ & 2018 & [39] \\
\hline
\end{tabular}

${ }^{\mathrm{a} C}$ ompression pressure

temperature. The authors associated the low value of conductivity with low mass density.

Itkis et al. [64] applied the bolometric method to determine the impact of the method of film preparation on the thermal properties of the final product. They obtained two types of CNT films. The first one was produced as a result of nanotube self-organization on a stainless-steel grid using the electric arc discharge process. (The name of the sample was aSWCNT film.) In the second method, they obtained a film using vacuum filtration from SWCNT dispersion. (The sample name was pSWCNT.) As for the method of preparation, the first film demonstrated lower packing density than the second one. The thickness of the aSWCNT and pSWCNT samples was 35 and $100 \mathrm{~nm}$, and the thermal conductivity values were 75 and $30 \mathrm{~W} / \mathrm{mK}$. In both films, a monotonic increase in thermal conductivity with temperature was observed. In the case of the aSWCNT film network, junctions were characterized with weaker contact than in pSWCNT, so thermal conductivity was lower.

Kong et al. [31, 39] analyzed a three-dimensional carbon nanotube network composed of vaCNTs bridged with randomly oriented secondary CNTs. This 3D structure was obtained with a two-step process. First, primary vaCNTs were created, and then, Ni particles were deposited on these CNTs. Ni particles acted as a catalyst and initiated the creation of secondary CNTs in the subsequent synthesis. In their research, they determined the impact of the network structure on the value of thermal conductivity using the freestanding sensor-based 3- $\omega$ technique. As a result of development of secondary CNTs for the 3D system of the array density of $5.6 \times 10^{8} \mathrm{CNT} / \mathrm{cm}^{2}$, thermal conductivity improved by over $55 \%$ from 9.3 to $19.8 \mathrm{~W} / \mathrm{mK}$. However, when the array density increased over $7.2 \times 10^{8} \mathrm{CNT} / \mathrm{cm}^{2}$, the presence of secondary CNTs deteriorated thermal conductivity in comparison with the primary CNT array. This phenomenon was explained by increased density of defects and too large tube-tube.

\section{Impact of annealing}

The process of obtaining and purifying CNTs has a significant effect on their properties. One of the main factors impacting these properties is the process of 
annealing of the final product, because it eliminates contaminants from the material, affects the internal ordering thereof and decreases the number of defects in the structure and, additionally, changes density, the effect of which was described above. The research conducted by Hone et al. [18, 75], Lin et al. [80] and Zhang et al. [71, 81] demonstrates the positive impact of annealing on thermal conductivity of CNTs.

Hone et al. [18, 75] obtained a film from the SWCNT which were aligned in the magnetic field and subjected to vacuum annealing at $1200{ }^{\circ} \mathrm{C}$. This film was compared with an unannealed film. They explained the improvement in thermal conductivity by removal from CNTs of acidic contaminants which changed the conduction mechanism.

Using LFA, Lin et al. [80] demonstrated that the low value of defects in single nanotubes causes increased thermal conductivity and that the annealing process affects the degree of ordering and the decrease in the number of defects present. Additionally, they found that CNT bundles have lower value of thermal conductivity, because the tube-tube interactions reduce the effective thermal conductivity of an individual CNT.

In other works, Zhang et al. [71, 81] described bulk MWCNTs obtained using CVD method through decomposition of propylene and hydrogen on $\mathrm{Ni}$ catalyst. After purifying, the nanotubes obtained were subject to annealing at various temperatures $\left(1600{ }^{\circ} \mathrm{C}, 1800{ }^{\circ} \mathrm{C}, 2000{ }^{\circ} \mathrm{C}\right)$. They analyzed [81] the change in the structure of bulk MWCNTs after annealing and found that the higher the annealing temperature, the higher the density, up to $1.45 \mathrm{~g} / \mathrm{cm}^{3}$ for the temperature of $2000{ }^{\circ} \mathrm{C}$. The measurements of the thermal properties of disk-shaped MWCNT samples demonstrated that an increase in annealing temperature, i.e., in density, caused an increase in the value of thermal conductivity from 2.8 to $4.2 \mathrm{~W} / \mathrm{mK}$ and thermal diffusivity. The impact of annealing on a change in internal ordering and on an increase in density of CNTs in the networks, as well as its relationship with an increase in thermal conductivity, was also presented by Yang et al. [82] and Ivanov et al. [65]. Yang et al. [82] obtained buckypapers from MWCNTs synthesized using the CVD method in the presence of an Fe catalyst. Then, they sintered the buckypapers under different temperatures between 500 and $1500{ }^{\circ} \mathrm{C}$ in a vacuum. They observed that the thermal conductivity value of buckypapers differs with the increase in sintering temperature from 1.5 to
$10.5 \mathrm{~W} / \mathrm{mK}$. In their study, Ivanov et al. [65] recorded an increase in thermal conductivity up to $400 \%$ for vaCNT after annealing it at $2800{ }^{\circ} \mathrm{C}$, which once again demonstrates how important it is to avoid defects in the material.

The results of the above-mentioned studies are presented in Table 6 .

Impact of direction of measurement and alignment

The direction of measurement with regard to the direction of CNTs in the sample is also significant, because thermal conductivity takes place along CNTs, and not across them. Some measurement methods, such as LFA, are based on the approximation that heat flow is one-directional [80]. That assumption was used by Lee et al. [8] in order to measure cross-plane conductivity. In their works, they also measured the in-plane thermal conductivity using the hot-disk method. Similar research was conducted by Misak et al. [83], but they conducted inplane measurements using LFA and out-of-plane measurements using hot-disk method. That approach to the deliberations on CNT thermal conductivity demonstrated that, depending on the direction of measurement, the values could be significantly different and that although a material was a conductor in one direction, it could be borderline semiconductor/insulator in the other one. In both papers, the authors showed that in-plane thermal conductivity is significantly higher than out-plane thermal conductivity. The in-plane measurement was $25 \mathrm{~W} / \mathrm{mK}$ [83] and $150 \mathrm{~W} / \mathrm{mK}$ [8], while out-of-plane thermal conductivities have the same value in both papers: $0.1 \mathrm{~W} / \mathrm{mK}$.

The impact of the direction of measurement on the value of thermal conductivity was also specified by Qiu et al. They then measured the values of thermal conductivity for all the three directions: $x$-plane direction, $y$-across the sample and $z$-in the thickness direction which amounted, respectively, to $127 \mathrm{~W} / \mathrm{mK}, 42 \mathrm{~W} / \mathrm{mK}$ and $4 \mathrm{~W} / \mathrm{mK}$. They also suggested that haCNTs are ordered more permanently than buckypaper or a CNT mat. Additionally, they observed that the change in orientation of CNTs from vertical to horizontal improves the thermal conductivity in the plane and reduces the overall thermal contact resistance for haCNT.

It follows from the above research that films made of CNTs have the properties of anisotropic materials. 
Table 6 Impact of annealing on thermal conductivity

\begin{tabular}{|c|c|c|c|c|c|c|}
\hline \multicolumn{7}{|c|}{ Impact of annealing on thermal conductivity } \\
\hline Type of CNT & Method of synthesis & Method of measurement & Annealing conditions & $K(\mathrm{~W} / \mathrm{mK})$ & Year & References \\
\hline \multirow[t]{3}{*}{ CNT bulk } & \multirow[t]{3}{*}{$\mathrm{CVD} / \mathrm{Ni}$ cat. } & \multirow[t]{3}{*}{ LFA } & $1600^{\circ} \mathrm{C} / 3 \mathrm{~min}$ & 2.8 & \multirow[t]{3}{*}{2005} & \multirow[t]{3}{*}{ [81] } \\
\hline & & & $1800^{\circ} \mathrm{C} / 3 \mathrm{~min}$ & 3.2 & & \\
\hline & & & $2000{ }^{\circ} \mathrm{C} / 3 \mathrm{~min}$ & 4.2 & & \\
\hline \multirow[t]{4}{*}{ vaCNT films } & \multirow[t]{4}{*}{ CVD } & \multirow[t]{4}{*}{ LFA } & VANTA3 unannealed & 3.0 & \multirow[t]{4}{*}{2006} & \multirow[t]{4}{*}[65]{} \\
\hline & & & VANTA3 annealed at $2800{ }^{\circ} \mathrm{C}$ & 15 & & \\
\hline & & & VANTA4 unannealed & 3.0 & & \\
\hline & & & VANTA4 annealed at $2800{ }^{\circ} \mathrm{C}$ & 10 & & \\
\hline \multirow[t]{4}{*}{ CNT buckypapers } & \multirow[t]{4}{*}{ Commercial CNT } & \multirow[t]{4}{*}{ Steady-state method } & Unannealed & 1.5 & \multirow[t]{4}{*}{2010} & \multirow[t]{4}{*}[82]{} \\
\hline & & & $900{ }^{\circ} \mathrm{C}$ & 4.5 & & \\
\hline & & & $1200{ }^{\circ} \mathrm{C}$ & 7.0 & & \\
\hline & & & $1500^{\circ} \mathrm{C}$ & 10.5 & & \\
\hline
\end{tabular}

The value of thermal conductivity along CNTs is much higher, sometimes even by four orders of magnitude, than in other directions. These deliberations led to research into the impact of magnetic field on ordering of CNTs in films and thus to improvement of thermal conductivity of materials. Such works were described by Fisher et al. [84] and Gonnet et al. [77]. They used SWCNTs to obtain mats in the magnetic field of the value of 7 and $26 \mathrm{~T}$ (Fisher's group) and 17.3 $\mathrm{T}$ (Gonnet's group). Like before, they demonstrated that the ordering of carbon nanotubes using a magnetic field improves their thermal conductivity significantly. The research results are listed in Table 7.

CNTs in a film may also be ordered mechanically. One such solution has been suggested by Wang et al. [48] who obtained a sheet of buckypaper with aligned CNTs using the so-called domino pushing method which demonstrated good thermal conductivity of $153 \mathrm{~W} / \mathrm{mK}$ (parallel) and $72 \mathrm{~W} / \mathrm{mK}$ (cross direction). For comparison, they also obtained a sample of buckypapers with randomly oriented nanotubesthe value of thermal conductivity was $81 \mathrm{~W} / \mathrm{mK}$. They demonstrated that the ordering of nanotubes in a plane increases the thermal conductivity in the alignment direction.

\section{Practical use of CNTs in thermal devices}

For many years, CNTs have been considered for application in many fields, such as microelectronics, energy, automotive, coatings or composites. Taking into account the significance of thermal properties of carbon nanotubes, there are two main areas, in which they can be applied: functional materials and electronic devices. The former include a thermal interface material (TIM), the latter-thermoelectric devices. In the former group, high thermal conductivity is required, while in the latter-undesirable.

TIMs are materials applied between two interfaces-one that generates heat, like a microprocessor or a photonic integrated circuit, and another one that dissipates heat, such as a heat sink. Continuous and good heat dissipation is necessary in that type of devices, because it often protects expensive systems from overheating and damage and extends their lifespan. That is why it is necessary that a material applied as a TIM has high thermal conductivity value and effectively dissipates heat. Commercial TIMs are mainly polymer-based materials with different fillers or based on copper. Figure 16 presents the contact area between two surfaces with and without TIMs. It can be seen that TIMs increase the contact area and limit the air gaps, the thermal conductivity ratio of which is very poor-thus improving heat transmission in the unit. When characterizing materials, TIMs are often described using the value of thermal resistance instead of thermal conductivity. Formula 11 [5] describes the relationship between thermal 
Table 7 Impact of direction of measurement and alignment

\begin{tabular}{|c|c|c|c|c|c|c|}
\hline \multicolumn{7}{|c|}{ Impact of direction of measurement and aligned } \\
\hline Type of CNT & Method of synthesis & $\begin{array}{l}\text { Method of } \\
\text { measurement }\end{array}$ & $\begin{array}{l}\text { Additional } \\
\text { information }\end{array}$ & $\begin{array}{l}K(\mathrm{~W} / \\
\mathrm{mK})\end{array}$ & Year & References \\
\hline vaCNT & \multirow[t]{4}{*}{ CVD } & \multirow[t]{4}{*}{$3-\omega$ method } & - & 15 & \multirow[t]{4}{*}{2016} & \multirow[t]{4}{*}[37]{} \\
\hline haCNT- $z$ axis & & & +shear pressing & 4 & & \\
\hline haCNT-y axis & & & & 42 & & \\
\hline haCNT- $x$ axis & & & & 127 & & \\
\hline 7T-aligned SWCNT & \multirow[t]{2}{*}{ Pulse laser ablation } & \multirow{11}{*}{$\begin{array}{l}\text { Comparative } \\
\text { method }\end{array}$} & $295 \mathrm{~K}$ & 10 & \multirow[t]{2}{*}{2003} & \multirow[t]{2}{*}[84]{} \\
\hline 26T-aligned SWCNT & & & $295 \mathrm{~K}$ & 60 & & \\
\hline \multirow{3}{*}{$\begin{array}{l}\text { SWCNTs mats aligned under } 17.3 \mathrm{~T} \\
\text { (parallel) }\end{array}$} & \multirow[t]{9}{*}{ nd } & & $150 \mathrm{~K}$ & 15 & \multirow[t]{9}{*}{2006} & \multirow[t]{9}{*}[77]{} \\
\hline & & & $225 \mathrm{~K}$ & 28.5 & & \\
\hline & & & $300 \mathrm{~K}$ & 42 & & \\
\hline SWCNTs mats aligned under $17.3 \mathrm{~T}$ & & & $150 \mathrm{~K}$ & 4 & & \\
\hline \multirow[t]{2}{*}{ (perpendicular) } & & & $225 \mathrm{~K}$ & 12 & & \\
\hline & & & $275 \mathrm{~K}$ & 20 & & \\
\hline \multirow[t]{3}{*}{ SWCNT randomly oriented mats } & & & $150 \mathrm{~K}$ & 6 & & \\
\hline & & & $225 \mathrm{~K}$ & 12.5 & & \\
\hline & & & $300 \mathrm{~K}$ & 18 & & \\
\hline \multirow[t]{2}{*}{ Buckypaper CNT } & \multirow[t]{2}{*}{$\begin{array}{l}\text { CVD }+ \text { “domino } \\
\text { pushing” }\end{array}$} & \multirow[t]{2}{*}{ Steady state } & $\begin{array}{l}d=1.34 \mathrm{~g} / \mathrm{cm}^{3} \\
\text { parallel }\end{array}$ & 331 & \multirow[t]{3}{*}{2008} & \multirow[t]{2}{*}[48]{} \\
\hline & & & Cross direction & 72 & & \\
\hline Random buckypaper CNT & CVD & & Parallel & 81 & & \\
\hline
\end{tabular}

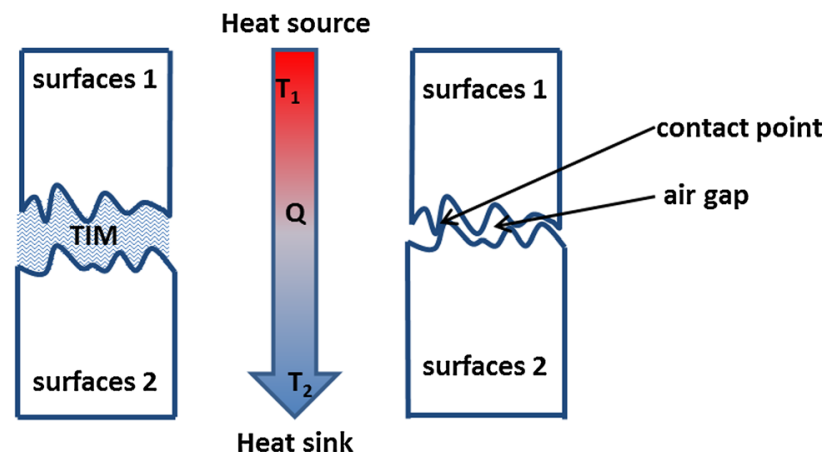

Figure 16 Scheme of contact area between two surfaces with TIM and without TIM. Created based on Razeeb et al. [5].

resistance, value of thermal conductivity and thickness of the TIM material.

$\Theta_{\mathrm{TIM}}=\frac{\mathrm{BLT}}{k_{\mathrm{TIM}}}+\Theta_{c 1}+\Theta_{c 2}\left(\frac{\mathrm{m}^{2} \mathrm{~K}}{\mathrm{~W}}\right)$

where $\Theta_{\mathrm{TIM}}$ is the total thermal resistance of TIM, $k_{\mathrm{TM}}$ is a thermal conductivity of TIM, BLT is a bond line thickness contact resistance of TIM, and $\Theta_{c 1}$ and $\Theta_{c 2}$ are contact resistance of the TIM with two bonding surfaces.
CNTs have been suggested for TIMs because of their mechanical and thermal properties. It has been observed that vaCNTs are perfect for that type of application, because they provide maximum heat conductivity, and thanks to the possibility to develop them, for example, on a Si surface, the result is a forest with a relatively significant packing density, thus providing better heat transmission capacity. Additionally, they are characterized by good chemical stability and low coefficient of thermal expansion [85]. Another important thing is that their transverse elastic modulus is low. In TIM units, nanotubes operate under a load. Due to their appropriate mechanical properties, they are flexible and adapt, without atomic-level defects, to the surfaces between which they are situated [86]. Figure 17 presents two ways of obtaining TIMs with CNTs, with flexible behavior of nanotubes under the applied force. Additionally, Fig. $17 \mathrm{~b}$ demonstrates the buckling of CNTs.

The application of CNTs as TIMs was first suggested by Fisher and Xu [87-89] — before that, CNTs were considered as potential fillers but not as an individual layer. They examined vaCNT on Si wafer 
(a)

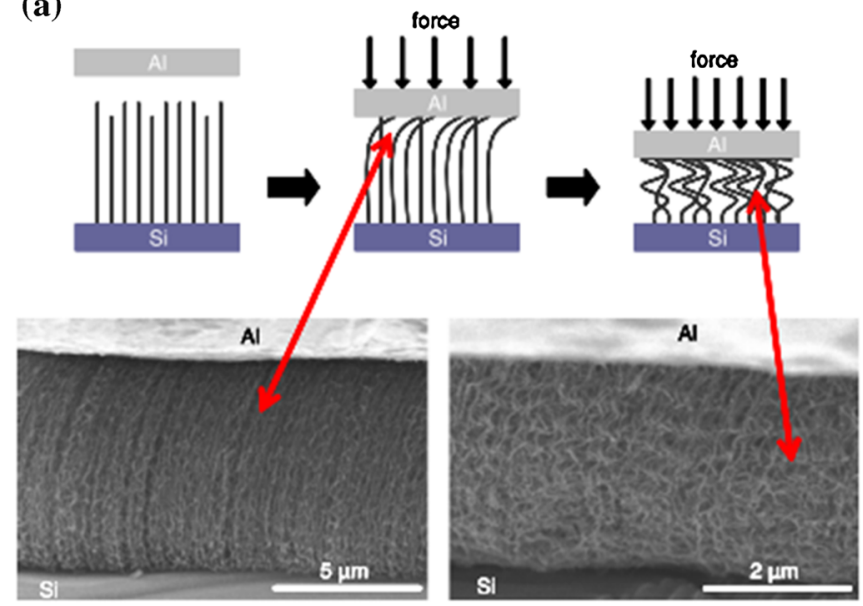

(b)

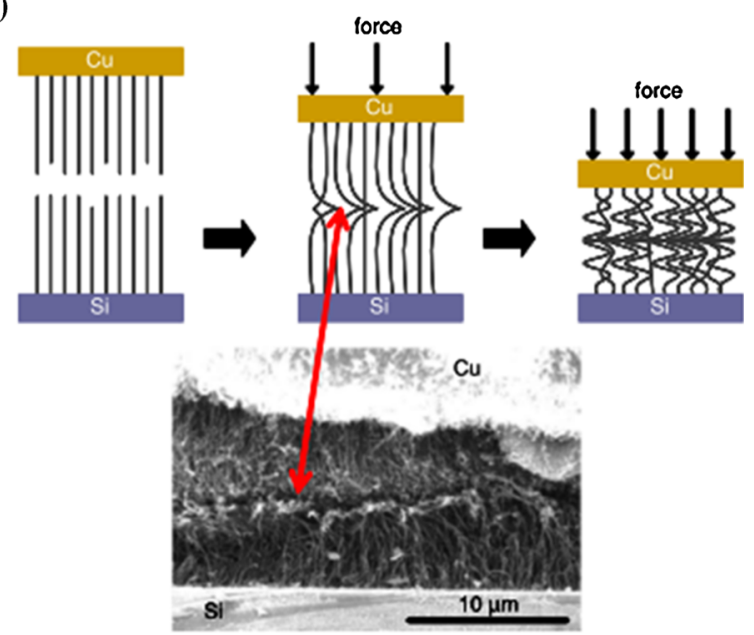

Figure 17 Contact mechanism and deformation CNT during TIM preparation. Adapted from Cola et al. [92] with permission from Elsevier.

coated with $\mathrm{Ni}$ or $\mathrm{Al}$ or Fe layer under $0.445 \mathrm{MPa}$. The thermal conductivity values obtained by them for the vaCNTs examined in TIM units were satisfactory. It was observed that the main factor limiting the effectiveness of CNT-TIMs in comparison with the extraordinary thermal conductivity of a single nanotube is high thermal resistance between the CNT and the substrate, on which it is situated. In their subsequent studies, they examined various units with different substrate materials and different coated layer materials. In the analyzed units, they measured the value of effective thermal conductivity to reach approximately $80 \mathrm{~W} / \mathrm{mK}$ [87].

Further studies related to TIM materials mainly consisted of introducing various modifications for the purpose of improving heat transmission. Tong et al. [52] suggested applying a layer of indium in order to reduce the resistance between the CNT layer and the surface layer. Kong et al. [39] suggested increasing the thermal conductivity value of a CNT foil by developing three-dimensional networks in order to increase the thermal capacity in the TIM materials. The results of that research were described in Part 4.1. The studies of application of vaCNTs as TIMs were also conducted by Peacock et al. [90]. They examined the impact of pressure and thickness of the layer on thermal resistance. Moreover, Chen et al. [57] used vaCNTs as TIMS for application in vibrational devices such as piezoelectric transformers.

In the case of measurements of thermal values of units that may be potentially applied as TIMs, the techniques most commonly used are LFA [80], thermoreflectance technique $[53,57]$ and steady-state measurements [87]. More information on TIMs based on CNTs may be found in the review articles of Razeeb et al. [5], Hansson et al. [91], Prasher et al. [41] and Cola et al. [92].

Another field, where the thermal properties of CNTs are significant, is thermoelectric devices. These devices have the ability to harvest electricity from waste heat. Such an array consists of metal or semiconductor materials which convert gradient of temperature into electrical voltage (Fig. 18). That phenomenon results from Seebeck effect, and the effectiveness of that type of materials is described using Formula 12 [1].

$\eta=\frac{T_{\mathrm{h}}-T_{\mathrm{c}}}{T_{\mathrm{h}}} * \frac{-1+\sqrt{1+Z T}}{\frac{T_{\mathrm{c}}}{T_{\mathrm{h}}}+\sqrt{1+Z T}}$

where $T_{\mathrm{h}}$ and $T_{\mathrm{c}}$ are the hot-end and cold-end temperatures of the sample, ZT is a figure of merit in the application temperature and is described by Formula 13:

$Z T=\frac{S^{2} \sigma T}{k}$

where $S$ is Seebeck coefficient, $k$ and $\sigma$ are thermal and electrical conductivities, $T$ is an absolute temperature. As can be noted, in order for the device to reach maximum capacity of processing waste thermal energy into electricity, it must be characterized by a high value of Seebeck coefficient and electrical conductivity, while demonstrating the lowest possible value of thermal conductivity. 
Figure 18 Schematic of thermoelectric generation module. Adapted from Yang et al. [1] with permission from Wiley.

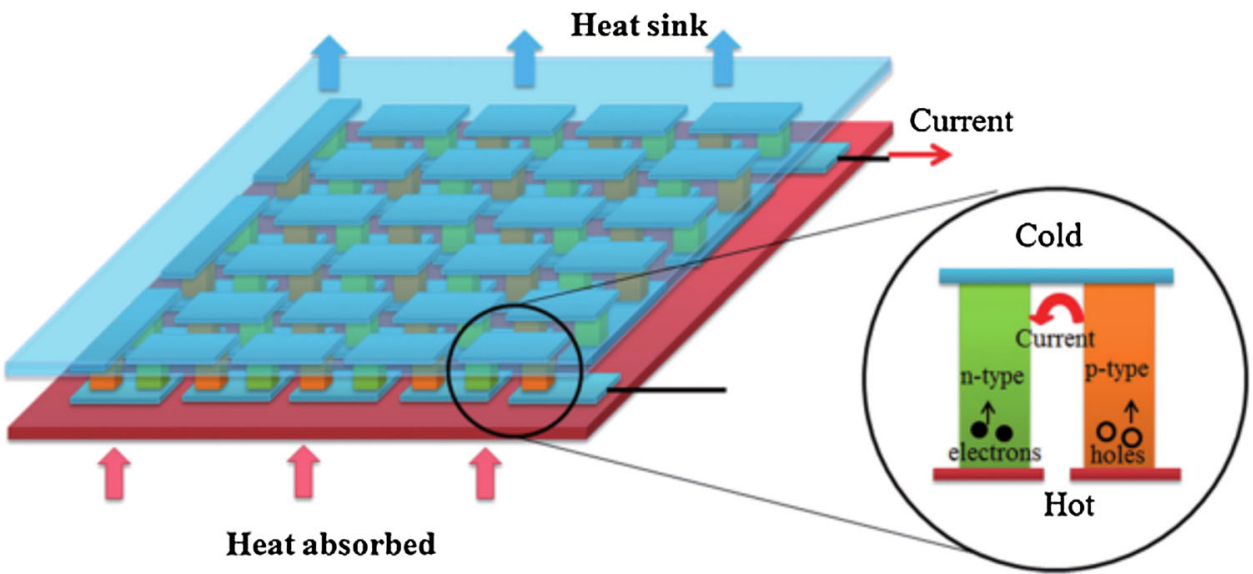

The main advantages of CNTs which make them eagerly and effectively used as substrate materials for doping for the purpose of adapting them to transmission of an electric charge and in TE devices include [4]:

1. Large and porous surface area, on which redox particles may be adsorbed.

2. CNT films demonstrate morphological stability in numerous solvents.

3. $\pi$-electron system is sensitive to the surfacemediate redox reaction, and it is not necessary to create covalent bonds to generate large swings in the carrier density injected by physisorbed molecules.

Avery et al. [93] were the first ones to conduct an extensive and systematic examination of s-SWCNTs, demonstrating the relationship between the band gap, carrier density and diameter of CNTs on the thermopower and power factor of semiconducting SWCNTs.

They applied the first-principle density functional theory to calculate the value of thermopower for various CNTs. The results obtained for semiconducting CNTs were much better than for the CNT of metallic character. The best result of thermopower $1285 \mu \mathrm{V} / \mathrm{K}$ was obtained for a pure $(7,5) \mathrm{CNT}$ film. On the basis of the theoretical results obtained, they conducted a series of experimental studies. They obtained films based on the s-SWCNTs that were practically completely cleaned of the metallic fraction of nanotubes. It follows from the experimental research that, for neat s-SWCNTs, the peak power factors were approximately $340 \mu \mathrm{W} / \mathrm{mK}^{2}$ at the optimum value of the electronic band gap of ca. 1.1-1.2 eV. They also observed that, depending on diameter of nanotubes and on the method of doping, it is possible to increase the value of electrical conductivity and to decrease the value of thermal conductivity, thus improving the figure of merit.

The published studies on the application of nanotubes as thermoelectric devices were mainly associated with the possibility to improve the capacity of that type of systems through modification of nanotubes, e.g., through doping with imidazoles [94], diazonium salts [95], sodium- or potassium-crown ether complex [96, 97], benzyl viologen or triethyloxonium hexachloroantimonate [93, 96, 98], encapsulated Co molecules [99] or C60 [95] into CNTs, and others. More information on thermoelectric materials based on CNTs and various modifications can be found in the review articles by Blackburn et al. [4], Chakraborty et al. [100], Yang et al. [1], Yamamoto and Fukuyama [101].

\section{Conclusion and future outlook}

Carbon nanotube thermal conductivity may be measured using different methods. In our study, we reviewed both contact and contactless methods and analyzed how the change in material structure affects the value of thermal conductivity, concentrating on the arrays made of nanotubes such as films, buckypaper or bundled CNTs. Each method described has its advantages and disadvantages, which are presented in Table 8.

Additionally, during the literature review we concentrated on various CNT films because, in our opinion, they have the best application potential for the future. The thermal conductivity values for various types of films are different, and the values 
Table 8 Advantages and disadvantages of thermal conductance measurements method

\begin{tabular}{|c|c|c|}
\hline Method & Advantages & Disadvantages \\
\hline $\begin{array}{l}\text { Mathematical } \\
\text { simulation }\end{array}$ & $\begin{array}{l}\text { Low cost } \\
\text { For all types of systems of CNT }\end{array}$ & $\begin{array}{l}\text { Determination of proper measurement assumptions is difficult } \\
\text { The more variables, the more difficult the calculations } \\
\text { Inaccuracy in modeling complex structures }\end{array}$ \\
\hline The 3- $\omega$ method & $\begin{array}{l}\text { Good for films and bulk materials } \\
\text { No need to know } C_{p} \text { or } d\end{array}$ & $\begin{array}{l}\text { The sample may be destroyed by overvoltage } \\
\text { The exact dimensions of the sample must be provided } \\
\text { Signal intensity close to noise intensity }\end{array}$ \\
\hline Steady state & $\begin{array}{l}\text { Easy to conduct } \\
\text { Good for rigid samples }\end{array}$ & $\begin{array}{l}\text { The effects of measurement conditions on the obtained values } \\
\text { are significant-a vacuum chamber is necessary } \\
\text { Improper for powders or elastic samples } \\
\text { Sample dimensions need to be provided }\end{array}$ \\
\hline $\begin{array}{l}\text { Parallel thermal } \\
\text { conductance }\end{array}$ & $\begin{array}{l}\text { Good for flexible samples and fibers } \\
\text { Easy to conduct } \\
\text { Possibility of measurements at different } \\
\text { temperatures }\end{array}$ & $\begin{array}{l}\text { Improper for powders } \\
\text { The sample dimensions must be relatively significant and } \\
\text { specified exactly } \\
\text { The effects of measurement conditions on the obtained values } \\
\text { are significant - a vacuum chamber is necessary }\end{array}$ \\
\hline $\begin{array}{l}\text { Steady-state method } \\
\text { with IR thermometer }\end{array}$ & $\begin{array}{l}\text { Easy detection of temperature changes } \\
\text { Proper for measurements of films and } \\
\text { buckypapers }\end{array}$ & $\begin{array}{l}\text { The need to provide the exact sample dimensions } \\
\text { The impact of the environment on the sample has to be reduced }\end{array}$ \\
\hline Comparative method & $\begin{array}{l}\text { Proper for films, mats, etc. } \\
\text { Possibility of measurements at different } \\
\text { temperatures }\end{array}$ & $\begin{array}{l}\text { The need to know the temperature characteristics of the } \\
\text { reference material }\end{array}$ \\
\hline Laser flash analysis & $\begin{array}{l}\text { Possible measurements at different } \\
\text { temperatures } \\
\text { Easy data reduction } \\
\text { Low measurement error } \\
\text { A small amount of energy will suffice to heat } \\
\text { the sample up }\end{array}$ & $\begin{array}{l}\text { Needs superior quality vacuum environment in order to reduce } \\
\text { heat dissipation } \\
\text { Heat diffusion time needs to be taken into account in } \\
\text { calculations } \\
\text { The need to know the } C_{\mathrm{p}} \text { and } d \\
\text { One direction of measurements } \\
\text { Complicated for thin films - significant precision in } \\
\text { determination of dimensions of samples is necessary }\end{array}$ \\
\hline $\begin{array}{l}\text { Thermoreflectance } \\
\text { method }\end{array}$ & $\begin{array}{l}\text { Small amount of a sample will suffice } \\
\text { Good sensitivity to thermal interfaces and } \\
\text { conductivities of submicron thin films }\end{array}$ & $\begin{array}{l}\text { Laborious sample preparation } \\
\text { Smooth surface is required } \\
\text { Complex experimental setup }\end{array}$ \\
\hline Raman spectroscopy & $\begin{array}{l}\text { Noninvasive } \\
\text { Good for measurement of all types of CNTs } \\
\text { system } \\
\text { Submicron resolution } \\
C_{\mathrm{p}} \text { and } d \text { not required }\end{array}$ & $\begin{array}{l}\text { Significant inaccuracy of results - up to } 20 \% \\
\text { Knowledge of characteristics of the pump laser beam }\end{array}$ \\
\hline
\end{tabular}

between $0.1 \mathrm{~W} / \mathrm{mK}$ and more than $700 \mathrm{~W} / \mathrm{mK}$ are assumed for experiments at room temperature.

Analysis of the publications on that subject allows to determine the main factors which affect the value of thermal conductivity of CNT films.

The first factor is the measurement temperature-if it is increased, often the thermal conductivity of CNT films also increases up to a certain limit.

The thermal conductivity value is also significantly affected by the structure of CNTs within the film. The conduction mechanism suggested by Aliev et al. demonstrates that MWCNTs are better conductors than SWCNTs, because the neighboring layers in the former make up additional conduction paths. Additionally, the presence of defects in the CNT network significantly affects conductivity. Both theoretical calculations and experimental results demonstrated that an increase in defects reduces the value of thermal conductivity. 
As for the films made up of CNTs, the additional factors affecting thermal conductivity are network order and density. The conducted tests demonstrated that, regardless of the order of nanotubes within the film-both mechanical operations, such as "domino pushing" and alignment in magnetic field, set the CNTs in one direction which improves thermal conductivity in that direction. As for density, both 2D films and 3D arrays demonstrated that an increase in density to a certain level improves thermal conductivity, and after that level (typical for the given array) is exceeded, conductivity starts to decrease. An increase in density increases the possibility to develop conduction paths, while at the same time while at the same time high-density material prepared this way may have elevated amount of defects, which would have negative effect on the overall thermal transport processes.

CNT films are anisotropic materials, so the direction of measurement plays a significant role in determining the value of thermal conductivity. That value is much higher along than across nanotubes. That is why the value of thermal conductivity of CNT arrays should be accompanied by information on the plane in which the measurement was taken.

The last factors which are more dependent on the measurement method are precision of measurements and precision of sample preparation. In the case of some methods, such as PSTTR, it is very significant and slight deviations can bear a significant experimental error.

Having analyzed the articles published so far, the three main directions that should be examined in the future were presented.

In the publications, we found no information on experimental research into films made of nanotubes of specific chirality, and only a description of mathematical simulations for those types of networks. We are aware that today it is not easy to obtain the proper amount of nanotubes of specific parameters for preparing a film. However, if better methods of separating nanotubes in terms of their chirality are perfected, such research may provide interesting results.

Another aspect that was often overlooked was development and examination of films made of DWCNTs. All the papers we analyzed addressed research into films made of SWCNTs and MWCNTs. It should be noted that the thermal transport mechanisms in films made of SWCNTs and MWCNTs are different. As DWCNTs have not been examined, it may occur that they constitute a sort of bridge between these two types of nanotubes preserving the advantages of SWCNTs, but simultaneously having high stability and thermal conductivity of MWCNTs.

The last issue that should be addressed in the future is improvement not only of the very structure of nanotubes making up the film (e.g., through elimination of defects or selection of one type), but also of the contact between the surface materials, so as to arrive at the best method of limiting the impact of contact resistance in the network containing CNTs.

When these answers and solutions are provided, it will be possible to design materials with CNTs with greater precision for the given applications, which could be very useful in many areas of the modern life.

\section{Acknowledgements}

BK and DJ thank the National Centre for Research and Development, Poland (under the Lider program, Grant agreement LIDER/0001/L-8/16/NCBR/2017). DJ would also like to acknowledge the Ministry for Science and Higher Education for the scholarship for outstanding young scientists (0388/E-367/STYP/12/ 2017) and the Rector of the Silesian University of Technology in Gliwice for the Pro-Quality Grant (04/ 020/RGJ18/0057).

Open Access This article is distributed under the terms of the Creative Commons Attribution 4.0 International License (http://creativecommons.org/ licenses/by/4.0/), which permits unrestricted use, distribution, and reproduction in any medium, provided you give appropriate credit to the original author(s) and the source, provide a link to the Creative Commons license, and indicate if changes were made.

\section{References}

[1] Yang L, Chen ZG, Dargusch MS, Zou J (2018) High performance thermoelectric materials: progress and their applications. Adv Energy Mater 8:1-28. https://doi.org/10. 1002/aenm.201701797

[2] Liu M, Johnston MB, Snaith HJ (2013) Efficient planar heterojunction perovskite solar cells by vapour deposition. Nature 501:395-398. https://doi.org/10.1038/nature12509 
[3] Blaabjerg F, Liserre M, Ma K (2012) Power electronics converters for wind turbine systems. IEEE Trans Ind Appl 48:708-719. https://doi.org/10.1109/TIA.2011.2181290

[4] Blackburn JL, Ferguson AJ, Cho C, Grunlan JC (2018) Carbon-nanotube-based thermoelectric materials and devices. Adv Mater 30:1704386. https://doi.org/10.1002/adma. 201704386

[5] Razeeb KM, Dalton E, Cross GLW, Robinson AJ (2018) Present and future thermal interface materials for electronic devices. Int Mater Rev 63:1-21. https://doi.org/10.1080/0 9506608.2017.1296605

[6] Berber S, Kwon Y-K, Tomanek D (2000) Unusually high thermal conductivity of carbon nanotubes. Phys Rev Lett 84:4613-4616. https://doi.org/10.1103/PhysRevLett.84. 4613

[7] Faraji S, Stano KL, Yildiz O et al (2015) Ultralight anisotropic foams from layered aligned carbon nanotube sheets. Nanoscale. https://doi.org/10.1039/c5nr03899e

[8] Lee E, Salgado RA, Lee B et al (2018) Design of lithium cobalt oxide electrodes with high thermal conductivity and electrochemical performance using carbon nanotubes and diamond particles. Carbon N Y 129:702-710. https://doi. org/10.1016/j.carbon.2017.12.061

[9] Iijima S (1991) Helical microtubules of graphitic carbon. Nature 354:56-58. https://doi.org/10.1038/354056a0

[10] Pop E, Mann D, Wang Q et al (2006) Thermal conductance of an individual single-wall carbon nanotube above room temperature. Nano Lett 6:96-100. https://doi.org/10.1021/ NL052145F

[11] Lindsay L, Broido DA, Mingo N (2009) Lattice thermal conductivity of single-walled carbon nanotubes: beyond the relaxation time approximation and phonon-phonon scattering selection rules. Phys Rev B. https://doi.org/10.1103/ PhysRevB.80.125407

[12] Hone J, Whitney M, Piskoti C, Zettl A (1999) Thermal conductivity of single-walled carbon nanotubes. Phys Rev B 59:R2514-R2516. https://doi.org/10.1103/PhysRevB.59. R2514

[13] Pop E, Mann D, Wang Q et al (2006) Thermal conductance of an individual single-wall carbon nanotube above room temperature. Nano Lett 6:96-100. https://doi.org/10.1021/ NL052145F

[14] Marconnet AM, Panzer MA, Goodson KE (2013) Thermal conduction phenomena in carbon nanotubes and related nanostructured materials. Rev Mod Phys 85:1295-1326. h ttps://doi.org/10.1103/RevModPhys.85.1295

[15] Han Z, Fina A (2011) Thermal conductivity of carbon nanotubes and their polymer nanocomposites: a review. Prog Polym Sci 36:914-944. https://doi.org/10.1016/J.PR OGPOLYMSCI.2010.11.004
[16] Hone J (2001) Phonons and thermal properties of carbon nanotubes. In: Dresselhaus MS, Dresselhaus G, Avouris P (eds) Carbon nanotubes: synthesis, structure, properties, and applications. Springer, Berlin, pp 273-286

[17] Balandin AA (2011) Thermal properties of graphene and nanostructured carbon materials. Nat Mater 10:569-581. h ttps://doi.org/10.1038/nmat3064

[18] Hone J, Llaguno MC, Biercuk MJ et al (2002) Thermal properties of carbon nanotubes and nanotube-based materials. Appl Phys A Mater Sci Process 74:339-343. https://d oi.org/10.1007/s003390201277

[19] Maruyama S (2003) A molecular dynamics simulation of heat conduction of a finite length single-walled carbon nanotube. Microscale Thermophys Eng 7:41-50. https://d oi.org/10.1080/10893950390150467

[20] Han Z, Fina A (2011) Thermal conductivity of carbon nanotubes and their polymer nanocomposites: a review. Prog Polym Sci 36:914-944. https://doi.org/10.1016/j.prog polymsci.2010.11.004

[21] Grujicic M, Cao G, Gersten B (2004) Atomic-scale computations of the lattice contribution to thermal conductivity of single-walled carbon nanotubes. Mater Sci Eng B 107:204-216. https://doi.org/10.1016/J.MSEB.2003.11.012

[22] Osman MA, Srivastava D (2001) Temperature dependence of the thermal conductivity of single-wall carbon nanotubes. Nanotechnology 12(1):21-24. https://doi.org/10.10 88/0957-4484/12/1/305

[23] Che J, Çagin T, Goddard WA (2000) Thermal conductivity of carbon nanotubes. Nanotechnology 11:65-69. https://d oi.org/10.1088/0957-4484/11/2/305

[24] Evans WJ, Shen M, Keblinski P (2012) Inter-tube thermal conductance in carbon nanotubes arrays and bundles: effects of contact area and pressure. Appl Phys Lett 100:261908. https://doi.org/10.1063/1.4732100

[25] Yao Z, Wang J-S, Li B, Liu G-R (2005) Thermal conduction of carbon nanotubes using molecular dynamics. Phys Rev B 71:085417. https://doi.org/10.1103/PhysRevB.71. 085417

[26] Prasher RS, Hu XJ, Chalopin Y et al (2009) Turning carbon nanotubes from exceptional heat conductors into insulators. Phys Rev Lett 102:105901. https://doi.org/10.1103/PhysRe vLett.102.105901

[27] Boroushak SH, Ansari R, Ajori S (2018) Molecular dynamics simulations of the thermal conductivity of crosslinked functionalized single- and double-walled carbon nanotubes with polyethylene chains. Diam Relat Mater 86:173-178. https://doi.org/10.1016/J.DIAMOND.2018.04 .023

[28] Chalopin Y, Volz S, Mingo N (2009) Upper bound to the thermal conductivity of carbon nanotube pellets. J Appl 
Phys 105:084301-084301-5. https://doi.org/10.1063/1. 3088924

[29] Volkov AN, Zhigilei LV (2010) Scaling laws and mesoscopic modeling of thermal conductivity in carbon nanotube materials. Phys Rev Lett 104:215902. https://doi.org/ 10.1103/PhysRevLett.104.215902

[30] Volkov AN, Zhigilei LV (2012) Heat conduction in carbon nanotube materials: strong effect of intrinsic thermal conductivity of carbon nanotubes. Appl Phys Lett 101:043113. https://doi.org/10.1063/1.4737903

[31] Kong Q, Qiu L, Lim YD et al (2018) Thermal conductivity characterization of three dimensional carbon nanotube network using freestanding sensor-based $3 \omega$ technique. Surf Coat Technol 345:105-112. https://doi.org/10.1016/J. SURFCOAT.2018.03.090

[32] Choi TY, Poulikakos D, Tharian J, Sennhauser U (2005) Measurement of thermal conductivity of individual multiwalled carbon nanotubes by the 3- $\omega$ method. Appl Phys Lett $\quad 87: 013108-013108-3$. https://doi.org/10.1063/1. 1957118

[33] Hu XJ, Padilla AA, Xu J et al (2006) 3-Omega measurements of vertically oriented carbon nanotubes on silicon. J Heat Transf 128:1109-1113. https://doi.org/10.1115/1. 2352778

[34] Choi TY, Poulikakos D, Tharian J, Sennhauser U (2006) Measurement of the thermal conductivity of individual carbon nanotubes by the four-point three- $\omega$ method. Nano Lett 6:1589-1593. https://doi.org/10.1021/n1060331v

[35] Aliev AE, Guthy C, Zhang M et al (2007) Thermal transport in MWCNT sheets and yarns. Carbon Nanotube Yarns 45:2880-2888. https://doi.org/10.1016/J.CARBON.2007.1 0.010

[36] Aliev AE, Lima MH, Silverman EM, Baughman RH (2010) Thermal conductivity of multi-walled carbon nanotube sheets: radiation losses and quenching of phonon modes. Nanotechnology 21:035709. https://doi.org/10.108 8/0957-4484/21/3/035709

[37] Qiu L, Wang X, Su G et al (2016) Remarkably enhanced thermal transport based on a flexible horizontally-aligned carbon nanotube array film. Sci Rep 6:21014. https://doi. org/10.1038/srep21014

[38] Wang ZL, Li Q, Tang DW (2011) Experimental reconstruction of thermal parameters in CNT array multilayer structure. Int J Thermophys 32:1013-1024. https://doi.org/ 10.1007/s10765-011-0977-z

[39] Kong Q, Bodelot L, Lebental B et al (2018) Novel threedimensional carbon nanotube networks as high performance thermal interface materials. Carbon Nanotube Yarns 132:359-369. https://doi.org/10.1016/J.CARBON.2018.02. 052
[40] Pal SK, Son Y, Borca-Tasciuc T et al (2008) Thermal and electrical transport along MWCNT arrays grown on inconel substrates. J Mater Res 23:2099-2105. https://doi.org/10. 1557/jmr.2008.0256

[41] Prasher RS (2006) Thermal interface materials: historical perspective, status, and future directions. Proc IEEE 94(8):1571-1586. https://doi.org/10.1109/JPROC.2006. 879796

[42] Zawilski BM, Littleton RT, Tritt TM (2001) Description of the parallel thermal conductance technique for the measurement of the thermal conductivity of small diameter samples. Rev Sci Instrum 72:1770. https://doi.org/10.1063/ 1.1347980

[43] Jakubinek MB, Johnson MB, White MA et al (2012) Thermal and electrical conductivity of array-spun multiwalled carbon nanotube yarns. Carbon Nanotube Yarns 50:244-248. https://doi.org/10.1016/J.CARBON.2011.08. 041

[44] Niven JF, Johnson MB, Juckes SM et al (2016) Influence of annealing on thermal and electrical properties of carbon nanotube yarns. Carbon Nanotube Yarns 99:485-490. http s://doi.org/10.1016/J.CARBON.2015.12.014

[45] Pöhls J-H, Johnson MB, White MA et al (2012) Physical properties of carbon nanotube sheets drawn from nanotube arrays. Carbon Nanotube Yarns 50:4175-4183. https://doi. org/10.1016/J.CARBON.2012.04.067

[46] Gspann TS, Juckes SM, Niven JF et al (2017) High thermal conductivities of carbon nanotube films and micro-fibres and their dependence on morphology. Carbon N Y 114:160-168. https://doi.org/10.1016/J.CARBON.2016.12. 006

[47] Zhang L, Zhang G, Liu C, Fan S (2012) High-density carbon nanotube buckypapers with superior transport and mechanical properties. Nano Lett 12:4848-4852. https://d oi.org/10.1021/nl3023274

[48] Wang D, Song P, Liu C et al (2008) Highly oriented carbon nanotube papers made of aligned carbon nanotubes. Nanotechnology 19:075609. https://doi.org/10.1088/0957-448 4/19/7/075609

[49] Liu P, Fan Z, Mikhalchan A et al (2016) Continuous carbon nanotube-based fibers and films for applications requiring enhanced heat dissipation. ACS Appl Mater Interfaces 8:17461-17471. https://doi.org/10.1021/acsami.6b04114

[50] Parker WJ, Jenkins RJ, Butler CP, Abbott GL (1961) Flash method of determining thermal diffusivity, heat capacity, and thermal conductivity. J Appl Phys 32:1679-1684. h ttps://doi.org/10.1063/1.1728417

[51] Ohsone Y, Wu G, Dryden J et al (1999) Optical measurement of thermal contact conductance between wafer-like 
thin solid samples. J Heat Transf 121:954-963. https://doi. org/10.1115/1.2826086

[52] Tong T, Majumdar A, Zhao Y et al (2006) Indium assisted multiwalled carbon nanotube array thermal interface materials. In Proceedings of 10th intersociety conference on thermal and thermomechanical phenomena in electronics systems 2006 ITHERM 2006, pp 1406-1411. https://doi. org/10.1109/ITHERM.2006.1645509

[53] Tong T, Zhao Y, Delzeit L et al (2007) Dense vertically aligned multiwalled carbon nanotube arrays as thermal interface materials. IEEE Trans Compon Packag Technol 30:92-100. https://doi.org/10.1109/TCAPT.2007.892079

[54] Panzer MA, Zhang G, Mann D et al (2008) Thermal properties of metal-coated vertically aligned single-wall nanotube arrays. J Heat Transf 130:052401. https://doi.org/ 10.1115/1.2885159

[55] Yang DJ, Zhang Q, Chen G et al (2002) Thermal conductivity of multiwalled carbon nanotubes. Phys Rev B 66:165440. https://doi.org/10.1103/PhysRevB.66.165440

[56] Sugime H, Esconjauregui S, D’Arsié L et al (2015) Lowtemperature growth of carbon nanotube forests consisting of tubes with narrow inner spacing using co/al/mo catalyst on conductive supports. ACS Appl Mater Interfaces 7:16819-16827. https://doi.org/10.1021/acsami.5b04846

[57] Chen L, Ju B, Feng Z, Zhao Y (2018) Vertically aligned carbon nanotube arrays as thermal interface material for vibrational structure of piezoelectric transformer. Smart Mater Struct 27:075007. https://doi.org/10.1088/1361-665 $\mathrm{X} / \mathrm{aac} 077$

[58] Wang X, Zhong Z, Xu J (2005) Noncontact thermal characterization of multiwall carbon nanotubes. J Appl Phys 97:064302. https://doi.org/10.1063/1.1854725

[59] Xu Y, Zhang Y, Suhir E, Wang X (2006) Thermal properties of carbon nanotube array used for integrated circuit cooling. J Appl Phys 100:074302. https://doi.org/10.1063/ 1.2337254

[60] Périchon S, Lysenko V, Remaki B et al (1999) Measurement of porous silicon thermal conductivity by micro-Raman scattering. J Appl Phys 86:4700. https://doi.org/10. 1063/1.371424

[61] Stoib B, Filser S, Stötzel J et al (2014) Spatially resolved determination of thermal conductivity by Raman spectroscopy. Semicond Sci Technol 29:124005. https://doi.org/ 10.1088/0268-1242/29/12/124005

[62] Sahoo S, Chitturi VR, Agarwal R et al (2014) Thermal conductivity of freestanding single wall carbon nanotube sheet by Raman spectroscopy. ACS Appl Mater Interfaces 6:19958-19965. https://doi.org/10.1021/am505484z

[63] Li Q, Liu C, Wang X, Fan S (2009) Measuring the thermal conductivity of individual carbon nanotubes by the Raman shift method. Nanotechnology 20:145702. https://doi.org/ 10.1088/0957-4484/20/14/145702

[64] Itkis ME, Borondics F, Yu A, Haddon RC (2007) Thermal conductivity measurements of semitransparent single-walled carbon nanotube films by a bolometric technique. Nano Lett 7:900-904. https://doi.org/10.1021/n1062689x

[65] Ivanov I, Puretzky A, Eres G et al (2006) Fast and highly anisotropic thermal transport through vertically aligned carbon nanotube arrays. Appl Phys Lett 89:223110. http s://doi.org/10.1063/1.2397008

[66] Feng Y, Inoue T, An H et al (2018) Quantitative study of bundle size effect on thermal conductivity of single-walled carbon nanotubes. Appl Phys Lett 112:191904-1-1919045. https://doi.org/10.1063/1.5021696

[67] Yoshida S, Feng Y, Delacou C et al (2017) Morphology dependence of the thermal transport properties of singlewalled carbon nanotube thin films. Nanotechnology 28:185701. https://doi.org/10.1088/1361-6528/aa6698

[68] Chen H, Chen M, Di J et al (2012) Architecting threedimensional networks in carbon nanotube buckypapers for thermal interface materials. J Phys Chem C 116:3903-3909. https://doi.org/10.1021/jp2086158

[69] Shaikh S, Li L, Lafdi K, Huie J (2007) Thermal conductivity of an aligned carbon nanotube array. Carbon N Y 45:2608-2613. https://doi.org/10.1016/J.CARBON.2007.0 8.011

[70] Mingo N, Broido DA (2005) Length dependence of carbon nanotube thermal conductivity and the "problem of long waves”. Nano Lett 5(7):1221-1225. https://doi.org/10.102 1/NL050714D

[71] Zhang H-L, Li J-F, Zhang B-P et al (2007) Electrical and thermal properties of carbon nanotube bulk materials: experimental studies for the 328-958 K temperature range. Phys Rev B 75:205407. https://doi.org/10.1103/PhysRevB. 75.205407

[72] Duzynska A, Judek J, Zdrojek M (2014) Temperature-dependent nonlinear phonon behavior in high-density carbon nanotube thin films. Appl Phys Lett 105:213105. https://d oi.org/10.1063/1.4902522

[73] Duzynska A, Taube A, Korona KP et al (2015) Temperature-dependent thermal properties of single-walled carbon nanotube thin films. Appl Phys Lett 106:183108. https://d oi.org/10.1063/1.4919792

[74] Duzynska A, Swiniarski M, Wroblewska A et al (2016) Phonon properties in different types of single-walled carbon nanotube thin films probed by Raman spectroscopy. Carbon N Y 105:377-386. https://doi.org/10.1016/J.CAR BON.2016.04.064

[75] Hone J, Llaguno MC, Nemes NM et al (2000) Electrical and thermal transport properties of magnetically aligned 
single wall carbon nanotube films. Appl Phys Lett 77:666-668. https://doi.org/10.1063/1.127079

[76] Hone J, Llaguno MC, Biercuk MJ et al (2002) Thermal properties of carbon nanotubes and nanotube-based materials. Appl Phys 74(3):339-343. https://doi.org/10.1007/ s003390201277

[77] Gonnet P, Liang Z, Choi ES et al (2006) Thermal conductivity of magnetically aligned carbon nanotube buckypapers and nanocomposites. Curr Appl Phys 6:119-122. h ttps://doi.org/10.1016/J.CAP.2005.01.053

[78] Xie H, Cai A, Wang X (2007) Thermal diffusivity and conductivity of multiwalled carbon nanotube arrays. Phys Lett A 369:120-123. https://doi.org/10.1016/J.PHY SLETA.2007.02.079

[79] Hu XJ, Prasher RS, Lofgreen K (2007) Ultralow thermal conductivity of nanoparticle packed bed. Appl Phys Lett 91:203113. https://doi.org/10.1063/1.2814959

[80] Lin W, Shang J, Gu W, Wong CP (2012) Parametric study of intrinsic thermal transport in vertically aligned multiwalled carbon nanotubes using a laser flash technique. Carbon N Y 50:1591-1603. https://doi.org/10.1016/J.CAR BON.2011.11.038

[81] Zhang HL, Li JF, Yao KF, Chen LD (2005) Spark plasma sintering and thermal conductivity of carbon nanotube bulk materials. J Appl Phys 97:114310. https://doi.org/10.1063/ 1.1927286

[82] Yang K, He J, Puneet P et al (2010) Tuning electrical and thermal connectivity in multiwalled carbon nanotube buckypaper. J Phys Condens Matter 22:334215. https://doi. org/10.1088/0953-8984/22/33/334215

[83] Misak HE, Rutledge JL, Swenson ED, Mall S (2016) Thermal transport properties of dry spun carbon nanotube sheets. J Nanomater 2016:1-8. https://doi.org/10.1155/201 6/9174085

[84] Fischer JE, Zhou W, Vavro J et al (2003) Magnetically aligned single wall carbon nanotube films: preferred orientation and anisotropic transport properties. J Appl Phys 93:2157-2163. https://doi.org/10.1063/1.1536733

[85] Chakraborty P, Ma T, Zahiri AH, Cao L, Wang Y (2018) Carbon-based materials for thermoelectrics. Adv Condens Matter Phys. https://doi.org/10.1155/2018/3898479

[86] Peacock MA, Roy CK, Hamilton MC et al (2016) Characterization of transferred vertically aligned carbon nanotubes arrays as thermal interface materials. Int J Heat Mass Transf 97:94-100. https://doi.org/10.1016/J.IJHEATMAS STRANSFER.2016.01.071

[87] Xu J, Xu J, Fisher TS, Fisher TS (2004) Enhanced thermal contact conductance using carbon nanotube arrays. Int Soc Conf Therm Phenom 2:549-555. https://doi.org/10.1109/ ITHERM.2004.1318332
[88] Xu J, Fisher TS (2006) Enhancement of thermal interface materials with carbon nanotube arrays. Int $\mathrm{J}$ Heat Mass Transf 49:1658-1666. https://doi.org/10.1016/J.IJHEAT MASSTRANSFER.2005.09.039

[89] Cola BA, Xu X, Fisher TS (2007) Increased real contact in thermal interfaces: a carbon nanotube/foil material. Appl Phys Lett 90:093513. https://doi.org/10.1063/1.2644018

[90] Peacock MA, Roy CK, Hamilton MC et al (2016) Characterization of transferred vertically aligned carbon nanotubes arrays as thermal interface materials. Int J Heat Mass Transf 97:94-100. https://doi.org/10.1016/J.IJHEATMAS STRANSFER.2016.01.071

[91] Hansson J, Nilsson TMJ, Ye L, Liu J (2018) Novel nanostructured thermal interface materials: a review. Int Mater Rev 63:22-45. https://doi.org/10.1080/09506608.20 17.1301014

[92] Cola BA, Xu J, Fisher TS (2009) Contact mechanics and thermal conductance of carbon nanotube array interfaces. Int J Heat Mass Transf 52:3490-3503. https://doi.org/10. 1016/J.IJHEATMASSTRANSFER.2009.03.011

[93] Avery AD, Zhou BH, Lee J et al (2016) Tailored semiconducting carbon nanotube networks with enhanced thermoelectric properties. Nat Energy 1:16033. https://doi. org/10.1038/nenergy.2016.33

[94] Nakashima Y, Nakashima N, Fujigaya T (2017) Development of air-stable $n$-type single-walled carbon nanotubes by doping with 2-(2-methoxyphenyl)-1,3-dimethyl-2,3-dihydro-1H-benzo[d]imidazole and their thermoelectric properties. Synth Met 225:76-80. https://doi.org/10.1016/J. SYNTHMET.2016.11.042

[95] Kang YH, Lee Y-C, Lee C, Cho SY (2018) Influence of the incorporation of small conjugated molecules on the thermoelectric properties of carbon nanotubes. Org Electron 57:165-170. https://doi.org/10.1016/J.ORGEL.2018.03. 013

[96] MacLeod BA, Stanton NJ, Gould IE et al (2017) Large nand p-type thermoelectric power factors from doped semiconducting single-walled carbon nanotube thin films. Energy Environ Sci 10:2168-2179. https://doi.org/10.1039/ C7EE01130J

[97] Nonoguchi Y, Nakano M, Murayama T et al (2016) Simple salt-coordinated $n$-type nanocarbon materials stable in air. Adv Funct Mater 26:3021-3028. https://doi.org/10.1002/a dfm.201600179

[98] Norton-Baker B, Ihly R, Gould IE et al (2016) Polymer-free carbon nanotube thermoelectrics with improved charge carrier transport and power factor. ACS Energy Lett 1:1212-1220. https://doi.org/10.1021/acsenergylett.6b 00417 
[99] Fukumaru T, Fujigaya T, Nakashima N (2015) Development of $n$-type cobaltocene-encapsulated carbon nanotubes with remarkable thermoelectric property. Sci Rep 5:7951. https://doi.org/10.1038/srep07951

[100] Chakraborty P, Ma T, Zahiri AH et al (2018) Carbon-based materials for thermoelectrics. Adv Condens Matter Phys. https://doi.org/10.1155/2018/3898479

[101] Yamamoto T, Fukuyama H (2018) Possible high thermoelectric power in semiconducting carbon nanotubes - a case study of doped one-dimensional semiconductors. J Phys Soc Jpn 87:024707. https://doi.org/10.7566/JPSJ.87. 024707

[102] Yamane T, Nagai N, Katayama S-I, Todoki M (2002) Measurement of thermal conductivity of silicon dioxide thin films using a $3 \omega$ method. J Appl Phys 91:9772-9776. h ttps://doi.org/10.1063/1.1481958

[103] Zhao D, Qian X, Gu X et al (2016) Measurement techniques for thermal conductivity and interfacial thermal conductance of bulk and thin film materials. J Electron Packag 138:040802-040802-19. https://doi.org/10.1115/1. 4034605

[104] Brütting M, Hemberger F, Vidi S et al (2016) Determination of heat capacity by means of longitudinal guarded comparative calorimeter-correction methods. Int J Therm Sci 100:423-429. https://doi.org/10.1016/j.ijthermalsci.20 15.10 .022

[105] An X-H, Cheng J-H, Yin H-Q et al (2015) Thermal conductivity of high temperature fluoride molten salt determined by laser flash technique. Int $\mathrm{J}$ Heat Mass Transf 90:872-877. https://doi.org/10.1016/J.IJHEATMAS STRANSFER.2015.07.042

Publisher's Note Springer Nature remains neutral with regard to jurisdictional claims in published maps and institutional affiliations. 